Ocean Dynamics

June 2013, Volume 63 Issue 6 Pages 633-659

http://dx.doi.org/10.1007/s10236-013-0616-2

http://archimer.ifremer.fr/doc/00171/28206/

(C) Springer-Verlag Berlin Heidelberg 2013

\title{
A seasonal dipolar eddy near Ras Al Hamra (Sea of Oman)
}

\author{
L'Hegaret Pierre ${ }^{1,{ }^{*}}$, Lacour Leo ${ }^{1}$, Carton Xavier ${ }^{1,3}$, Roullet Guillaume ${ }^{1,3}$, Baraille Remy ${ }^{2}$, \\ Correard Stephanie ${ }^{2}$
}

${ }^{1}$ Univ Bretagne Occidentale, LPO, F-29200 Brest, France.

2 SHOM, F-31400 Toulouse, France.

${ }^{3}$ Ifremer, france

*Corresponding author : Pierre L’Hégaret, email address : pierre.Ihegaret@univ-brest.fr

\begin{abstract}
:
Trajectories and hydrological data from two Argo floats indicate that warm and salty water at 200-300-m depths was ejected from the coast of Oman, near Ras al Hamra, in spring 2008, 2011, and 2012. This warm and salty water, Persian Gulf Water (PGW), once ejected from the coast, recirculated cyclonically in the western Sea of Oman, but also flowed eastward along the Iranian and Pakistani coasts. There, it was expelled seaward by mesoscale eddies as shown by other float data. Seasonal maps of salinity were computed from all available Argo floats; they showed that, in spring, PGW is present in the middle and north of the Sea of Oman, contrary to fall, when the salinity maxima lie southeast of Ras al Hadd. The ejection of PGW from Ras al Hamra is related here to the influence of a mesoscale dipolar eddy which often appears near this cape in spring. The time-averaged and empirical orthogonal functions of altimetric maps over 11 years for this season confirm the frequent presence and the persistence of this feature. From surface currents and hydrology, deep currents were computed via thermal wind balance, and the associated shear and strain fields were obtained. This deformation field is intense near Ras al Hamra, with an offshore direction. This flow structure associated with the mesoscale dipole explains PGW ejection from the coast. This observation suggests that PGW distribution in the Northern Arabian Sea can be strongly influenced by seasonal mesoscale eddies.
\end{abstract}

Keywords : Sea of Oman, Outflow, Eddies, Argo floats 


\section{Introduction}

The Arabian/Persian Gulf (hereafter the Persian Gulf), located between the Arabian Peninsula and Iran, is a shallow sea, with maximum depth of $100 \mathrm{~m}$ near the Straits of Hormuz; the Persian Gulf is about $1000 \mathrm{~km}$ long and 350 $\mathrm{km}$ wide, and is oriented in a NW-SE direction; it opens on the Sea of Oman (or Gulf of Oman) via the Straits of Hormuz which are about $110 \mathrm{~m}$ deep and $56 \mathrm{~km}$ wide. The Persian Gulf experiences fast tidal currents, especially near the Straits and around islands, but residual currents are weak ([19]). The dominant northwesterly winds and the density gradients in the Persian Gulf induce a circulation that is mostly cyclonic, at least in its southeastern part, with an inflow of fresh Indian Ocean Surface Water (IOSW) from the Sea of Oman ([27], [20]). The Persian Gulf is subject to strong evaporation (more than $1.5 \mathrm{~m}$ of freshwater evaporates per year) which dominates precipitation; therefore salty waters are produced, in its northern and southwestern regions. These two regions feed a salty outflow through the straits, with maximal respective contributions in summer and in winter ([21], [3], [24], [28], [17]). The temperature and salinity of the outflow in the Straits of Hormuz are about $21^{\circ} \mathrm{C}$ and 40.8 in winter and $25^{\circ} \mathrm{C}$ and 39.3 in summer. On the contrary, the Sea of Oman is a deep basin with a narrow shelf; maximal depths are in excess of $3000 \mathrm{~m}$. There, the winds are more variable and are influenced by the monsoon. The circulation is variable (mesoscale eddies grow and decay in this sea); upwellings can occur near the Iranian coast ([18]).

Once in the Sea of Oman, the outflow from the Persian Gulf dives down the continental slope near of the Straits of Hormuz, mixes with surrounding waters and adjusts hydrostatically at about $250 \mathrm{~m}$ depth along the coast of Oman. This outflow water is called Persian Gulf Water (PGW). The outflow transport is 0.12 to $0.15 \mathrm{~Sv}$ ([11], [28]). Available observations indicate that this outflow follows the Omani coast down to Ras al Hadd in summer and then bifurcates southeastward; in winter, the PGW outflow progresses beyond Ras al Hadd, and follows the southern Omani coast ([3], [18]). The salinity of the PGW outflow decreases from 39.5 to 37.5 between the Straits of Hormuz and Ras al Hamra. The thermohaline properties of PGW along its the coast of Oman show two strong decays, one in the Straits and one in the western part of the Sea of Oman (see the local T/S diagrams in [18]). Also, a few measurements identified isolated patches of PGW in the middle of the Sea of Oman. A single occurence of a well characterized lens eddy of PGW is reported in [23]).

Recent modeling work suggests that the PGW outflow may leave the Omani coast near Ras al Hamra ([8]) but these theoretical results await a clear observational confirmation. Unfortunately, oceanographic cruises spanning the whole Sea of Oman are rare. Therefore, ARGO float data are used here. Previous work has already shown that the trajectory and thermohaline sections of these floats carry important information on the mesoscale dynamics 
in the Arabian Sea ([6]).

Our purpose is to confirm that PGW can be expelled from the outflow current near Ras al Hamra, to determine when and how this event takes place, and finally to explain the mechanism by which this occurs. After presenting the data and methods (section 2), the analysis of Argo floats trajectories and hydrological sections will show that PGW expulsion from the coast of Oman occurs preferentially in spring and occured at least thrice in the past five years (Section 3). Then, we will present horizontal maps of temperature and salinity at the depth of the PGW obtained by interpolation of float data, and we will contrast the situations in spring and in autumn (section 4). We will also show that a dipolar eddy exists and remains quasi-stationary near Ras al Hamra when PGW ejection occurs. Finally, we will relate the existence of this dipole with Rossby waves and the wind stress field at that period (section 5), and conclusions will be drawn.

\section{Material and methods}

Argo float data were obtained from the Coriolis data center at IFREMER in Brest (France). 26 floats drifted in the Northern Arabian Sea and in the Sea of Oman. Twelve of them covered the Sea of Oman only. The lifetime of these floats ranged from a few months to more than 4 years. Their cycle period (the time interval between two surfacings of the float) ranged from 4 to 10 days. Wrong hydrological data were discarded and so were floats which presented too many erroneous measurements. The accuracy of the float data was $\pm 0.002^{\circ} \mathrm{C}$ in temperature, \pm 0.005 in salinity, $1 \mathrm{~m}$ in depth, but data were provided only every $10 \mathrm{~m}$ from the surface down to $50 \mathrm{~m}$ depth, every $25 \mathrm{~m}$ down to 150 $\mathrm{m}$, every $50 \mathrm{~m}$ down to $300 \mathrm{~m}$ and then every $100 \mathrm{~m}$. Therefore, the water masses in the upper $300 \mathrm{~m}$ of the ocean were sampled over 13 vertical points. Here, three floats are presented in detail, to illustrate the expulsion of PGW from the coast into the central Sea of Oman or into the Arabian Sea, in recent years.

Each float provided many vertical profiles of temperature and salinity which are displayed here along the path of the float (this is called "temperature section" or "salinity section" below, though the abscissa is temporal). Note that the ARGO floats are positioned only when they surface. Therefore, we call "float trajectory" the segments linking the successive float surfacings. The deep (and exact) float trajectory is unknown. The float trajectories will be segmented to display separate events.

We obtained the Generalized Digital Environment Model (GDEM) climatology from http://www.usgodae.org/ and used it to create horizontal maps of temperature and salinity; these maps were then modified by inserting the float data according to the following procedure. First, each float measurement was converted into an anomaly by substracting the climatological value for 
the given month and position. Second, this pointwise anomaly was extended spatially with an isotropic Gaussian correlation function, weighted by the local number of data (the radius of the Gaussian was chosen as $\mathrm{L}=50 \mathrm{~km}$, typical of a mesoscale eddy). This correlation function was normalized to unity where data lay. Third, the resulting anomaly was added to the climatology.

To determine the surface circulation, altimetric maps were obtained from the CNES/AVISO data center. These maps display absolute dynamic topography $(\mathrm{ADT})$, with $1 / 4 \times 1 / 4$ degree resolution on a Mercator grid and daily interpolation; the mean sea level was a 7 -year mean of the sea surface topography. The error on along-track measurements of sea level was $3-4 \mathrm{~cm}([9])$.

For the years 2008-2012, three altimetric satellites (Jason 1 and 2, Envisat) were operational. For the Jason satellites, the inter-track distance at the Equator is $315 \mathrm{~km}$ and the repetitivity period of the orbit is 10 days; for Envisat, they are $80 \mathrm{~km}$ and 35 days. From the along-track data, gridded data were computed by AVISO via data merger and optimal interpolation (see [7]). The quality of the maps strongly depends on the quality of the mean topography of the ocean surface, calculated from hydrographic and satellite data. More information on MADT production is provided in [10], [12], [13] and [14].

To outline the cyclonic or anticyclonic motions at the sea surface, we created maps of "MADT anomaly", which is the difference between local MADT and its instantaneous spatial mean (note that this anomaly is different from SLA where the pointwise time average has been substracted from MADT).

These sea surface elevations were also studied from a statistical point of view, to show their recurrence in time; empirical orthogonal functions (EOF) were calculated to determine the spatial structure of variability; seasonal time averages were also computed. The surface currents were computed via geostrophy, from the pressure anomaly associated with the sea surface elevation. The deep currents were computed from hydrology via the thermal wind equations, using the surface currents as a reference.

To assess the dynamical influence of the winds on the surface circulation, winds were retrieved from the CERSAT data center with $1 / 4 \times 1 / 4$ degree resolution and monthly mean series were obtained by collocation of scatterometer data. Also, high-frequency winds were obtained from the European Center for Medium-Range Weather Forecast model, at $1 / 8 \times 1 / 8$ degree resolution with 6 -hour time lag. The wind stress curl was computed from these latter data. For the monthly means, the curl was time averaged and compared with that derived from the lower resolution data.

\section{Selected trajectories and hydrological sections of Argo floats in the Sea of Oman}

In the ARGO database, three floats were selected which exhibited loops in the western Sea of Oman, and offshore motion from the coast of Oman or from 


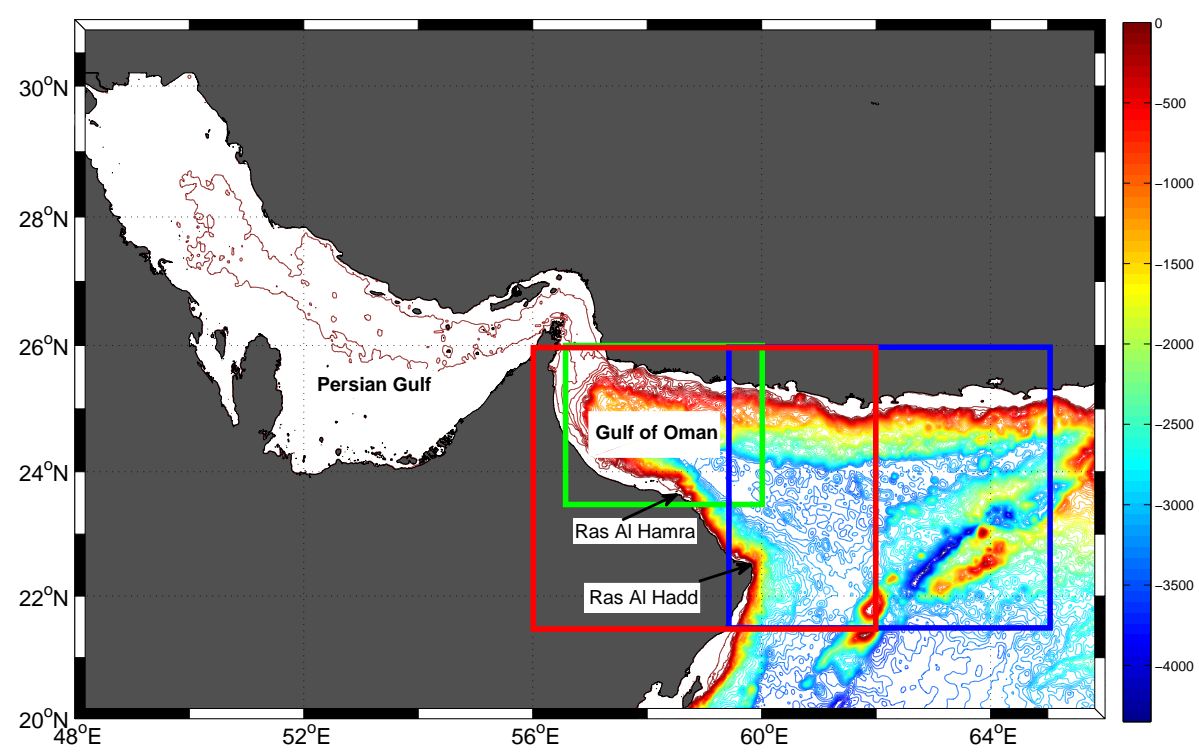

Fig. 1 Map of the Sea of Oman and Northern Arabian Sea bathymetry; the green box is the domain of evolution of float 2900804, the red box that of float 2901370 and the blue box that of float 6900902 .

the coast of Iran. These are Argo floats 2900804, 2901370 and 6900902 . Figure 1 presents their respective domains of evolution over the regional bathymetry.

\subsection{Analysis of ARGO float 2900804}

Float 2900804 was deployed December 14,2007 near $24.51^{\circ} N, 59.15^{\circ} E$. It was retrieved June 24,2008 near $24.02^{\circ} N, 58.05^{\circ} \mathrm{E}$. It performed 4-day cycles with a parking depth at $1000 \mathrm{~m}$. Its trajectory shows many cyclonic loops in the center of the western Sea of Oman. Figure 2 details small loops with radii of about $40 \mathrm{~km}$, northeast of Ras al Hamra from March 3 to April 16, 2008, and a larger loop along the continental slope from Iran to Oman, with a radius of $80 \mathrm{~km}$, from May 22 to June 23, 2008. Such a large cyclonic loop of a float in the Gulf of Oman had already been described by [18].

These loops are superimposed on the altimetric maps averaged over the given period. During the first period, the surface flow was composed of a cyclone near $58^{\circ} \mathrm{E}$ and of an anticyclone near $60^{\circ} \mathrm{E}$. The float trajectory looped 

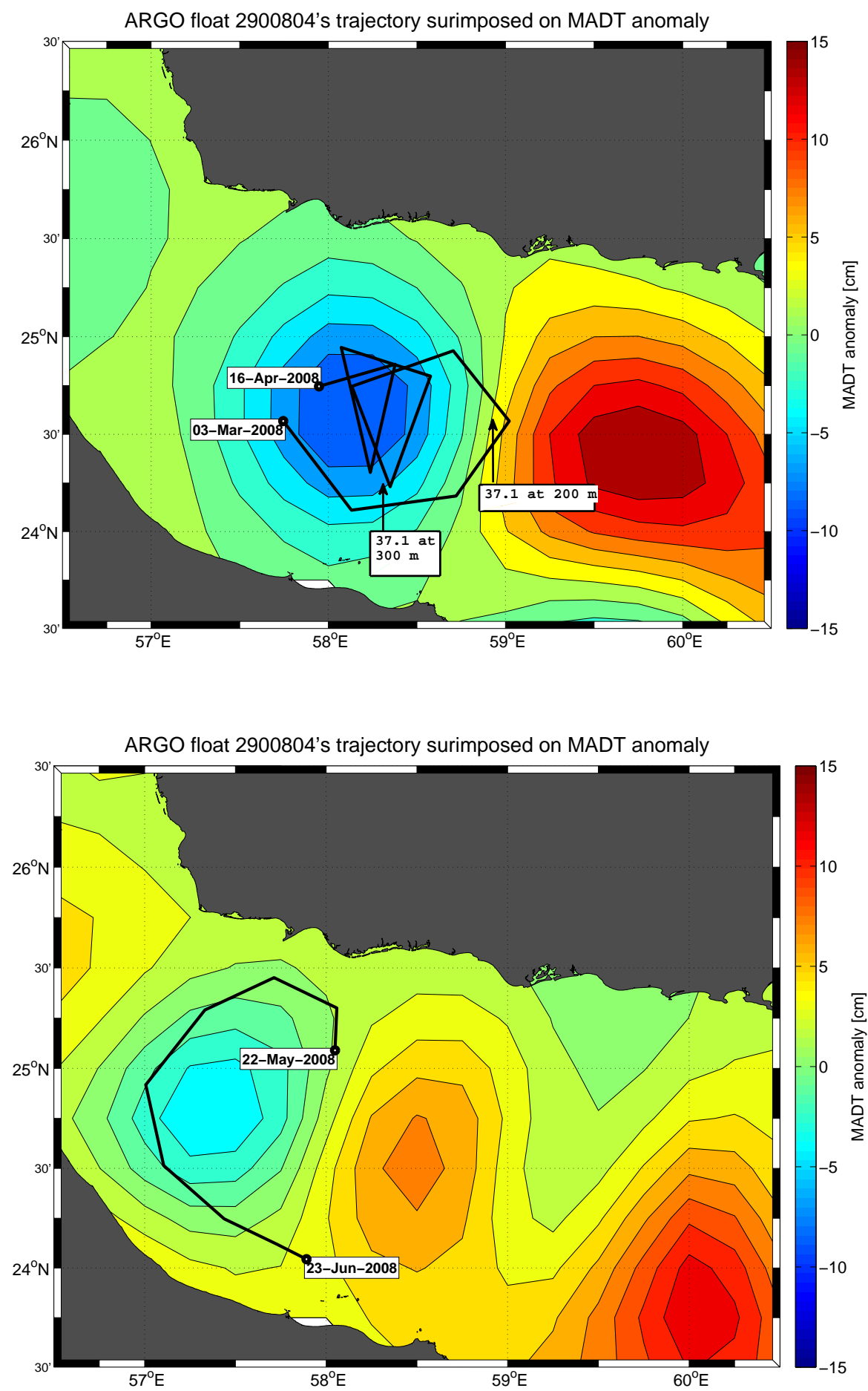

Fig. 2 Trajectory of Argo float 2900804 superimposed on MADT anomaly maps time averaged over each period; (top) period of March 3 - April 16, 2008; (bottom) period of May 22 - June 23, 2008, very high salinities (above 37) were measured along this part of the trajectory. 
mostly in the surface cyclone. In fact, the altimetric maps showed few changes in the surface circulation patterns from early February 2008 until end of April 2008 , and this surface dipole was very persistent.

During the second period, a clear correlation also existed between the surface topography and the float trajectory. The surface geostrophic currents reached about $0.3 \mathrm{~m} / \mathrm{s}$ and the average Lagrangian velocity for the float during this period was $0.2 \mathrm{~m} / \mathrm{s}$ in the same direction as the surface currents. The magnitude of this float velocity was comparable to that of currents at $900 \mathrm{~m}$ depth measured by [18]. Indeed, the cyclonic and anticyclonic gyres in the Sea of Oman have a deep reaching dynamic signature. Note also that, in June 2008, a small anticyclone appeared near $58-59^{\circ} \mathrm{E}$, between the large cyclone near $57^{\circ} \mathrm{E}$ and the large anticyclone again near $60^{\circ} \mathrm{E}$.

In brief, from early February until end of June 2008, the surface circulation in the western Sea of Oman evolved very slowly and the currents at $1000 \mathrm{~m}$ depth (obtained from the float displacements) faithfully reflected the surface flow.

The salinity section along the whole float trajectory (not shown) indicates that two high salinity events occured between 200 and $400 \mathrm{~m}$ depth, one end of March, beginning of April and the other end of May, and in June; in both cases, the float recorded salinities above 37 . Figure 3 zooms in on these two events.

On March 15, the salinity maximum at $200 \mathrm{~m}$ depth was measured at $24.5^{\circ} \mathrm{N}$, $59^{\circ} \mathrm{E}$, in the Sea of Oman, nearly on the axis between the cyclone and the anticyclone. The fresher water measured on March 23 indicates that the float also sampled the edge of the salinity anomaly measured a week earlier. A second salinity anomaly was measured, at $300 \mathrm{~m}$ depth, on March 27. This point was close to the continental slope and was likely to be located in the PGW slope current. Therefore, the salinity anomaly measured in mid Sea of Oman was probably a detached fragment from the slope current of PGW.

From May 22 to June 23, a very marked salinity anomaly (reaching 37.5) was measured by the float in the 200-300 m depth range (not shown). These recordings were performed by the float along the large cyclonic loop at the head of the Sea of Oman, firstly northward along the Iranian continental slope, then near the Straits of Hormuz, and finally southward along the Omani coast. Thus PGW could be found all along the northern continental slope of the Sea of Oman, at that time. Such a spread out PGW signature can have been formed :

- either by an outflow which changed direction with time (e.g. firstly along the Iranian coast, then along the Omani coast),

- or by an outflow with multiple branches,

- or by short-term pulses of this outflow ([1]),

- or finally by the cyclonic recirculation of PGW in the western part of the Sea of Oman, starting from the ejection of PGW from the slope currents near Ras al Hamra. 


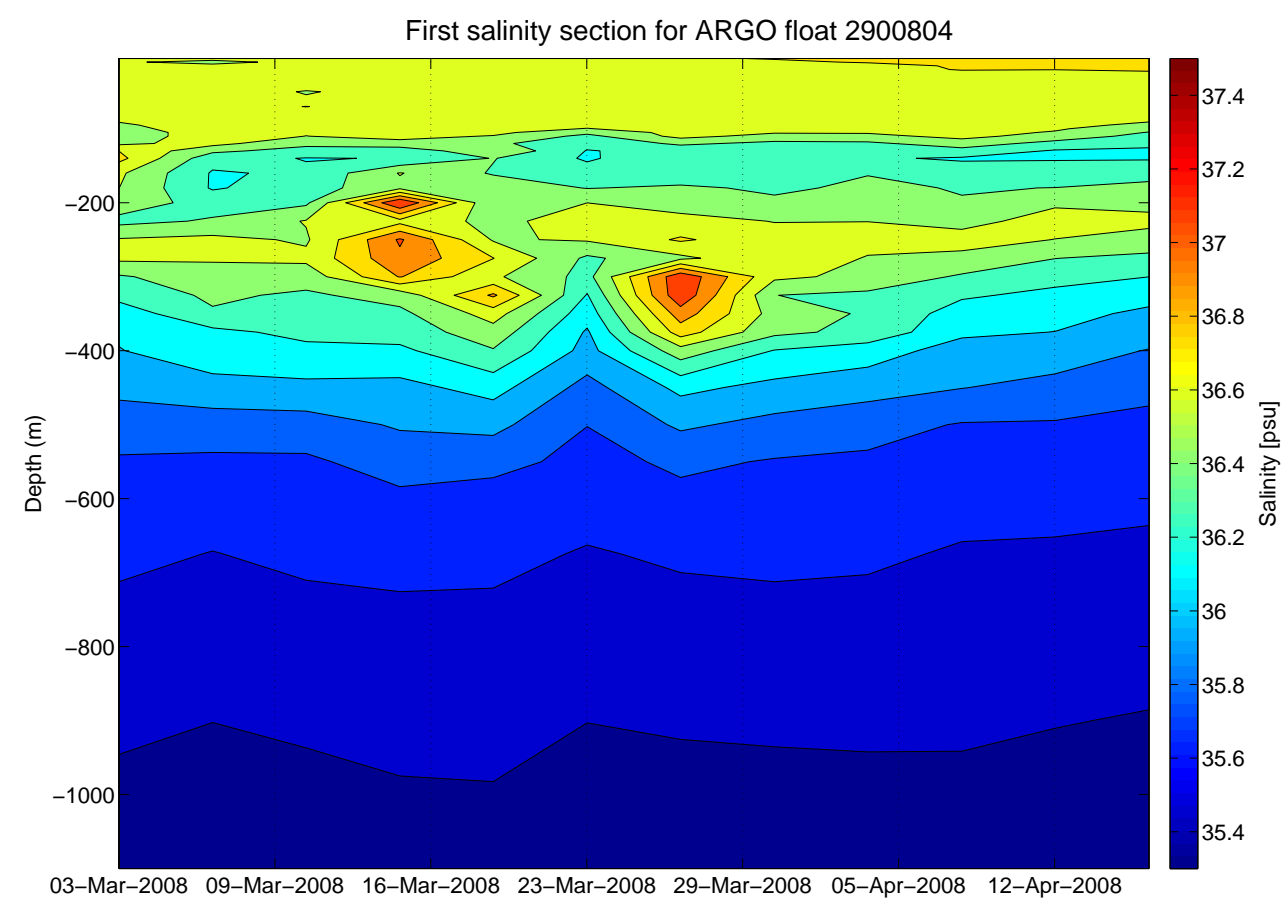

03-Mar-2008 09-Mar-2008 16-Mar-2008 23-Mar-2008 29-Mar-2008 05-Apr-2008 12-Apr-2008

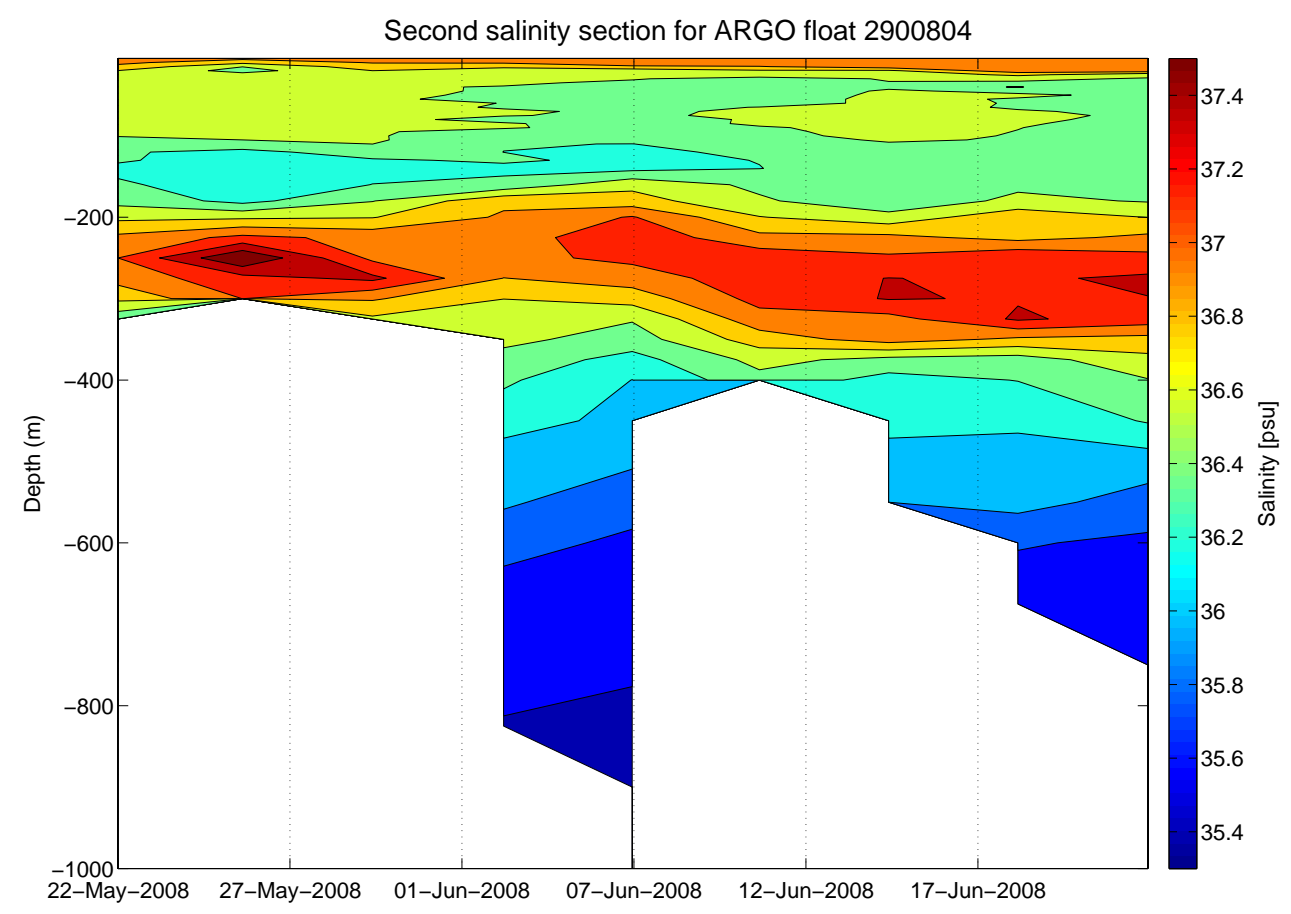

Fig. 3 Time versus depth diagram of salinity, as measured by Argo float 2900804, along its trajectory in the vicinity of Ras al Hamra; zoom on the March event (top); zoom on the May-June event (bottom). 
The March-April event supports this latter interpretation.

\subsection{Analysis of ARGO float 2901370}

Float 2901370 started its mission November 22, 2009 near $23.78^{\circ} \mathrm{N}, 60.80^{\circ} \mathrm{E}$ and the last data were collected for this study, June 3, 2012, when the float was near $24.51^{\circ} \mathrm{N}, 58.02^{\circ} \mathrm{E}$, with a parking depth at $250 \mathrm{~m}$. The whole float trajectory displayed many loops which ranged in size from 25 to $200 \mathrm{~km}$. The loops in the western Sea of Oman are shown in detail below.

From April 2 to June 30, 2011, the float performed two cyclonic loops, with radii $60 \mathrm{~km}$, east of Ras al Hamra, but with a superimposed westward motion (see figure 4). Then, from June 30 to December 14, 2011, the float drifted along the Iranian coast, first eastward and then westward. In a third stage (shown on figure 5), the float performed cyclonic loops near $24.5^{\circ} \mathrm{N}, 58^{\circ} \mathrm{E}$, with radii 30 to $40 \mathrm{~km}$, near the center of the Sea of Oman, from December 14, 2011 to April 24, 2012. Finally, a smaller-scale cyclonic trajectory with radii $25-30 \mathrm{~km}$ was followed by the float until mid June, west of $58^{\circ} \mathrm{E}$ (see again figure 4).

Figure 5 shows two segments of the float trajectory, superimposed on the altimetric maps averaged over each period. In spring 2011, the float performed two counter clockwise loops correlated with a surface cyclone west of a large anticyclone, with a radius of $40 \mathrm{~km}$. In April 2012, the float performed two cyclonic loops west of Ras al Hamra, mostly following the surface cyclone with the same radius as in spring. The correlation between the float trajectory and the altimetric signal was weaker here than in 2008; the radii of the loops being similar to the horizontal resolution of the altimetric data (about $30 \mathrm{~km}$ ) may be the cause for this weaker correlation. But, as in 2008, the dipole was present near Ras al Hamra and the float trajectory indicated fluid ejection from the Omani coast, and its recirculation in the western Sea of Oman.

The salinity section along the float trajectory shows the presence of PGW at 150 to $350 \mathrm{~m}$ depth, with salinity maxima above 37, in spring 2011 and in spring 2012 (see figure 6); this occured, as the float was looping cyclonically west of Ras al Hamra. During both springs, the altimetric maps show the presence of the dipole at this location.

In summary, the presence of a dipolar eddy, with a cyclone west of Ras al Hamra and an anticyclone east of this cape, most likely ejected salty PGW into the middle of the Sea of Oman; it also advected PGW across the head of the Sea of Oman thereafter. 

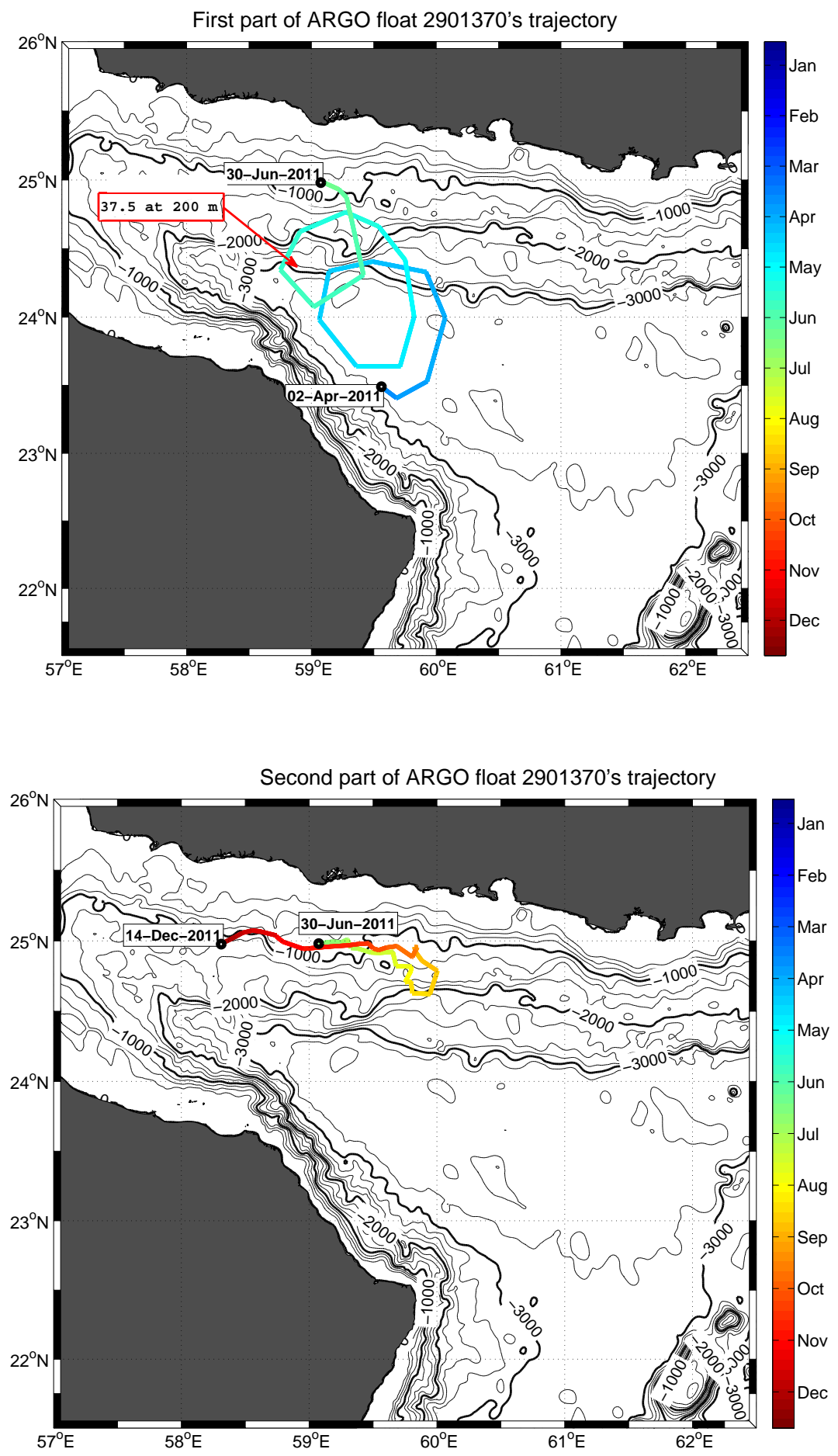


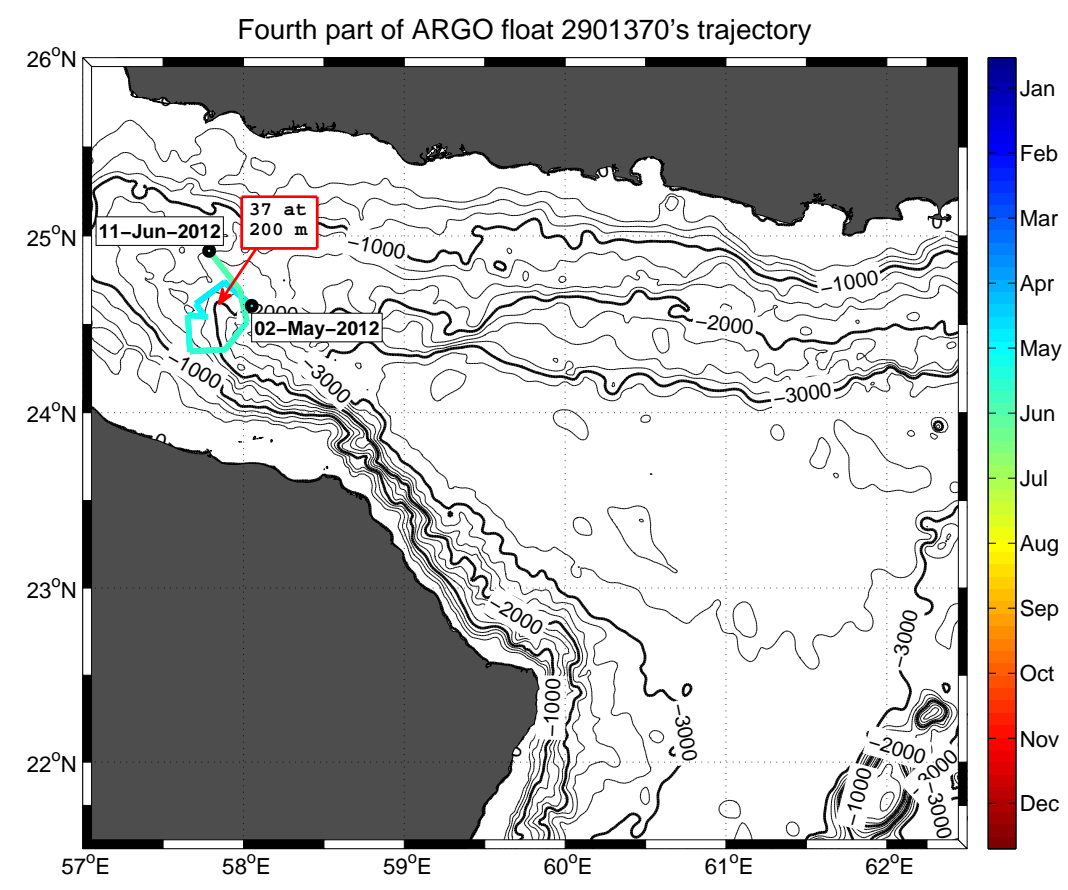

Fig. 4 Trajectory of Argo float 2901370 superimposed on bathymetry; from April 2 to June 30, 2011 (previous page, top); from June 30 to December 14, 2011, salinities above 36.5 were measured all along this trajectory(previous page, bottom); from May 2 to June 11,2012 (this page).

\subsection{Analysis of ARGO float 6900902}

Float 6900902 was deployed March 03,2011 near $22.28^{\circ} \mathrm{N}, 60.85^{\circ} \mathrm{E}$. It was retrieved June 24, 2012 near $24.02^{\circ} N, 58.05^{\circ} \mathrm{E}$. It performed 5 -day cycles with a parking depth at $700 \mathrm{~m}$. After an anticyclonic and a cyclonic loop near Ras al Hadd, it drifted northeastward towards the coast of Pakistan. There it performed two small anticyclonic loops (from November 2011 until February 2012; see figure 7), followed by a large cyclonic loop (from February to May 2012 , shown on figure 8 ) and then by an oscillatory motion at $24^{\circ} N$ between $63.5^{\circ} \mathrm{E}$ and $64.5^{\circ} \mathrm{E}$ (until June 2012). The part of its measurements of interest for the present study is that performed between November 2011 and May 2012. The large loop in the surface float trajectory, with radius close to $50 \mathrm{~km}$, clearly followed the surface motions as shown by figure 8 . The smaller loops, with radii smaller than, or equal to $30 \mathrm{~km}$, were more poorly correlated with altimetry (these radii are below the resolution of the gridded altimetric data). The float velocity along these loops (and in particular along the large loop) was about $4 \mathrm{~cm} / \mathrm{s}$; this velocity is about half the estimated swirl velocity of 


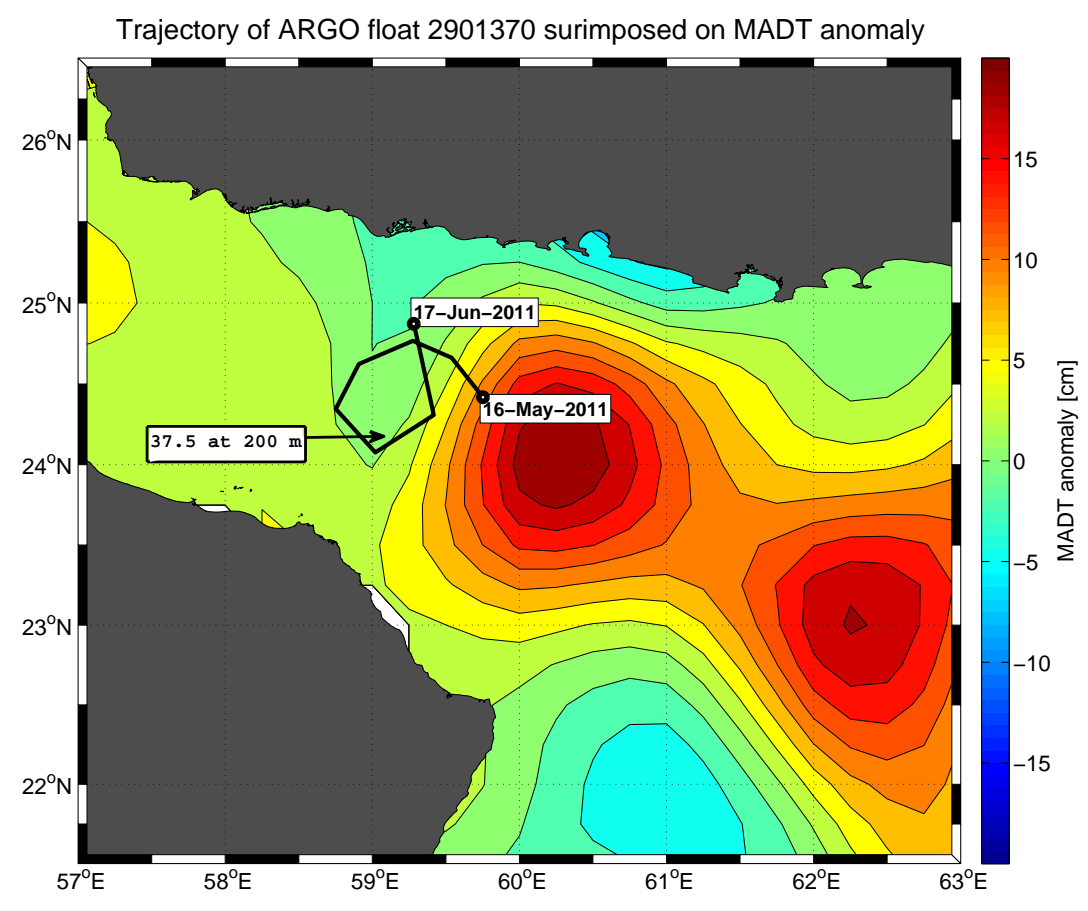

Trajectory of ARGO float 2901370 (third part) surimposed on MADT anomaly

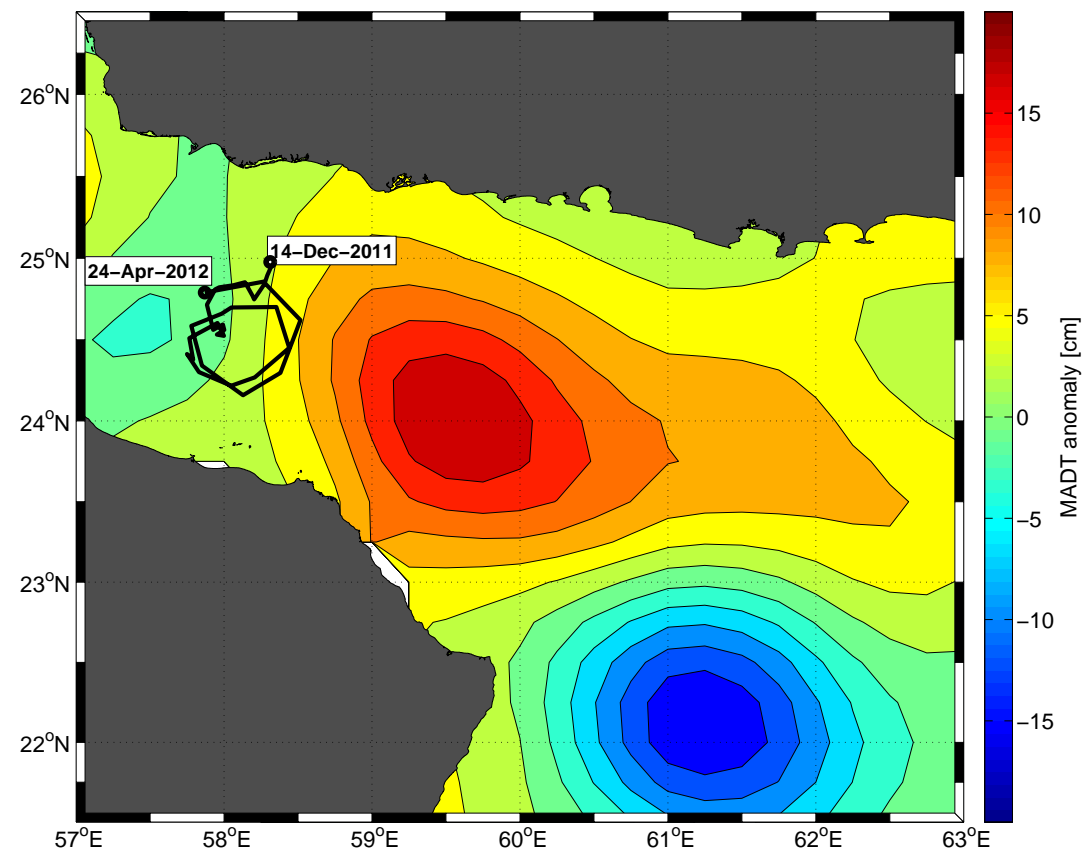

Fig. 5 Trajectory of Argo float 2901370 superimposed on MADT anomaly maps near Ras al Hamra; (top) period of May 16 to June 17, 2011 ; (bottom) period of April 4 to 24, 2012. 


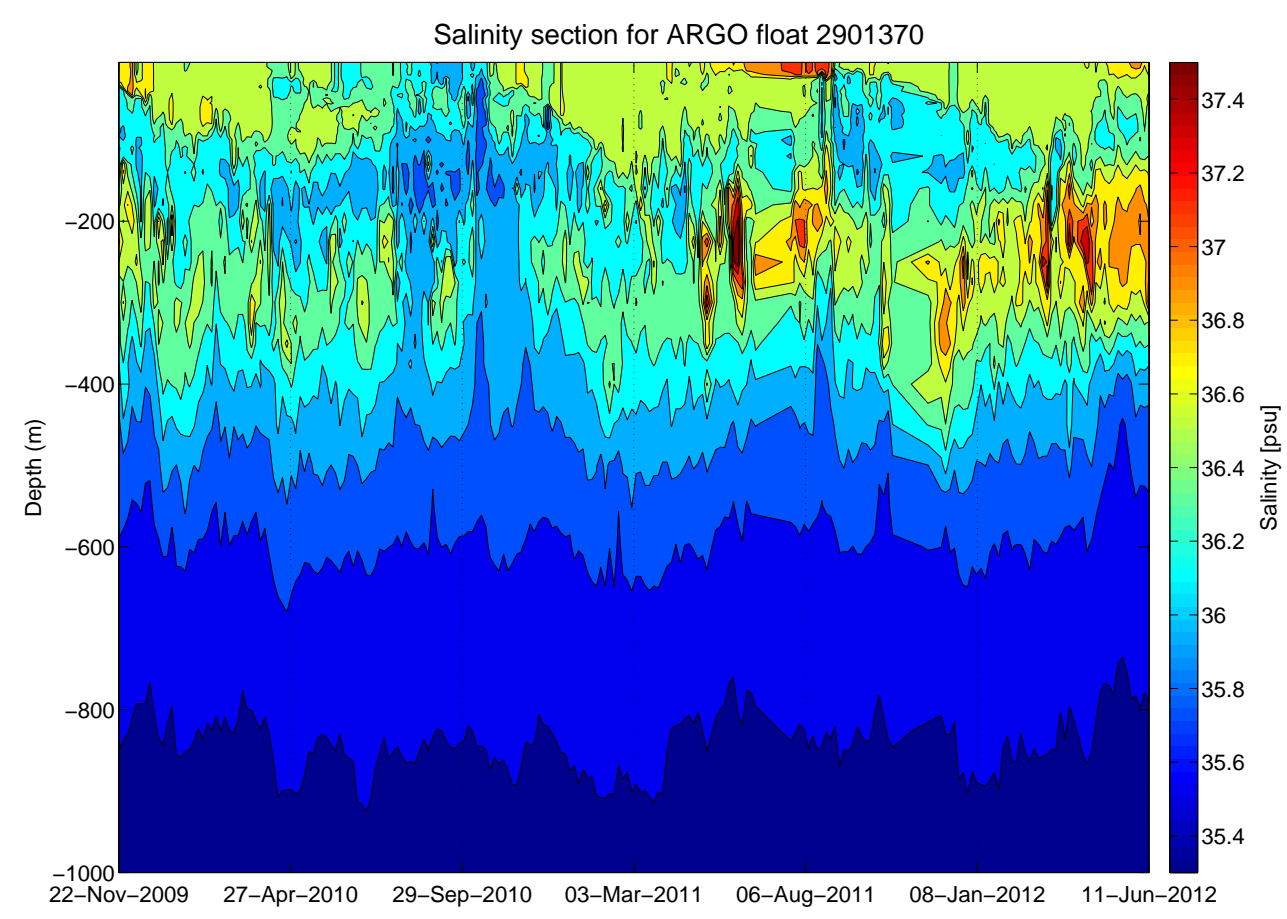

Fig. 6 Time versus depth diagram of salinity, as measured by Argo float 2901370, along its trajectory.

the surface cyclone at $64.5^{\circ} E, 23^{\circ} N$ in March-May 2012.

The time evolution of sea surface height (not shown here) shows the formation of the small surface anticyclone end of January 2012 , near $24.5^{\circ} \mathrm{N}, 64^{\circ} \mathrm{E}$, surrounded by two small cyclones at $24.5^{\circ} \mathrm{N}, 62.75^{\circ} \mathrm{E}$ and at $24^{\circ} \mathrm{N}, 65^{\circ} \mathrm{E}$. The small anticyclone was then advected southwestward by the small cyclone on its western side, hence the southwestward drift of float 6900902 during that period, superimposed on the loops. The small anticyclone reached $23^{\circ} \mathrm{N}, 62^{\circ} \mathrm{E}$ in early March 2012, while the two small cyclones merged on its northeastern side. The large cyclone in which the float was trapped in April was the result of this merger.

The time versus depth section of salinity is displayed on figure 9; contrary to the September 2011 - January 2012 period, when salinity was lower than 36.3 at 200-400 m depths (not shown here), the salinities in March - May were in excess of 36.5, especially in the 200-300 m depth range. Associated with temperatures around $19^{\circ} \mathrm{C}$, this water mass was clearly PGW. The presence of PGW at such eastern longitudes must be the result of its expulsion from 


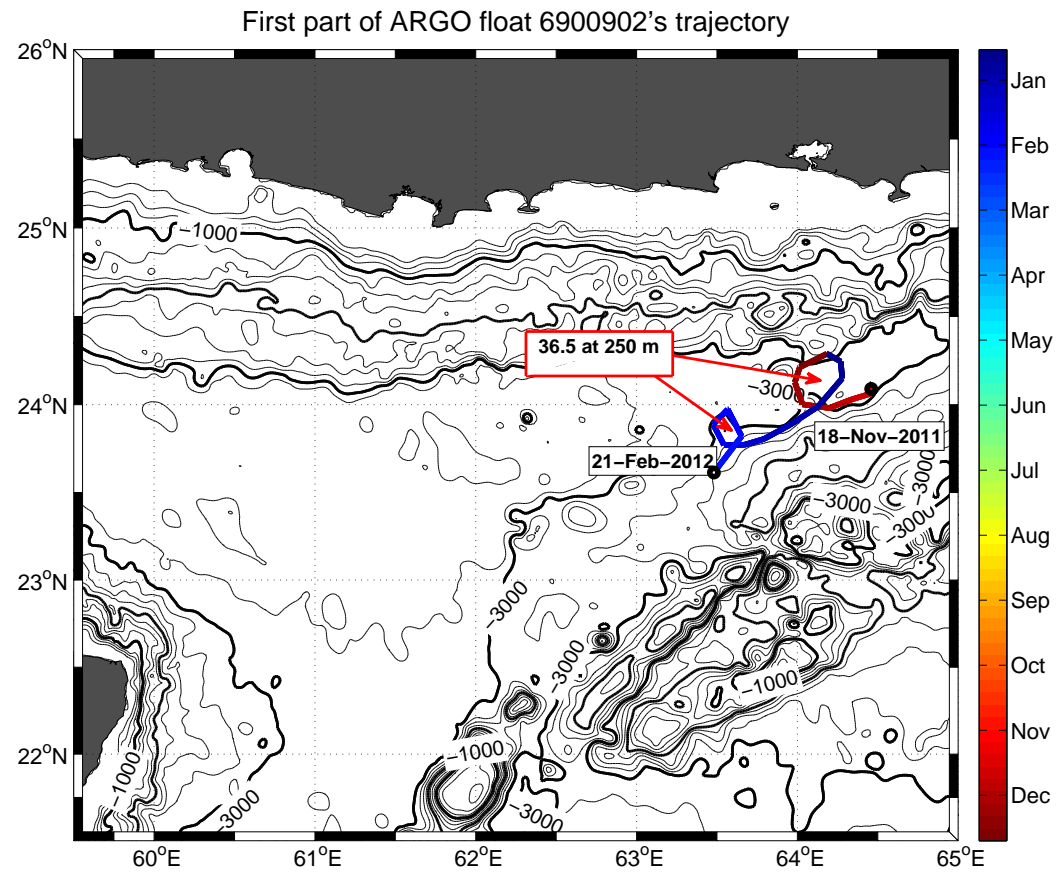

Fig. 7 Trajectory of Argo float 6900902 superimposed on bathymetry, from November 18, 2011 to February 21, 2012.

the Omani continental slope earlier on (compatible with our previous observations), and of its advection along the Iranian and Pakistani coasts, either via currents or by eddies. The small cyclone-anticyclone pair can have advected this PGW away from the Pakistani coast.

In summary, these observations show expulsion of PGW from the slope current in April-June due to quasi-steady eddy pairs near Ras al Hamra. These eddies clearly had a deep reaching flow field, as indicated by the float motions. This high-salinity water then recirculated westward (and cyclonically) in the Sea of Oman and eastward along the Iranian and Pakistani coasts, where it was again expelled offshore by eddies.

\section{Temperature, salinity and sea level elevation signatures of the dipole}

To provide more general evidence of PGW expulsion from the Omani continental slope, seasonal salinity maps are now established via interpolation of 


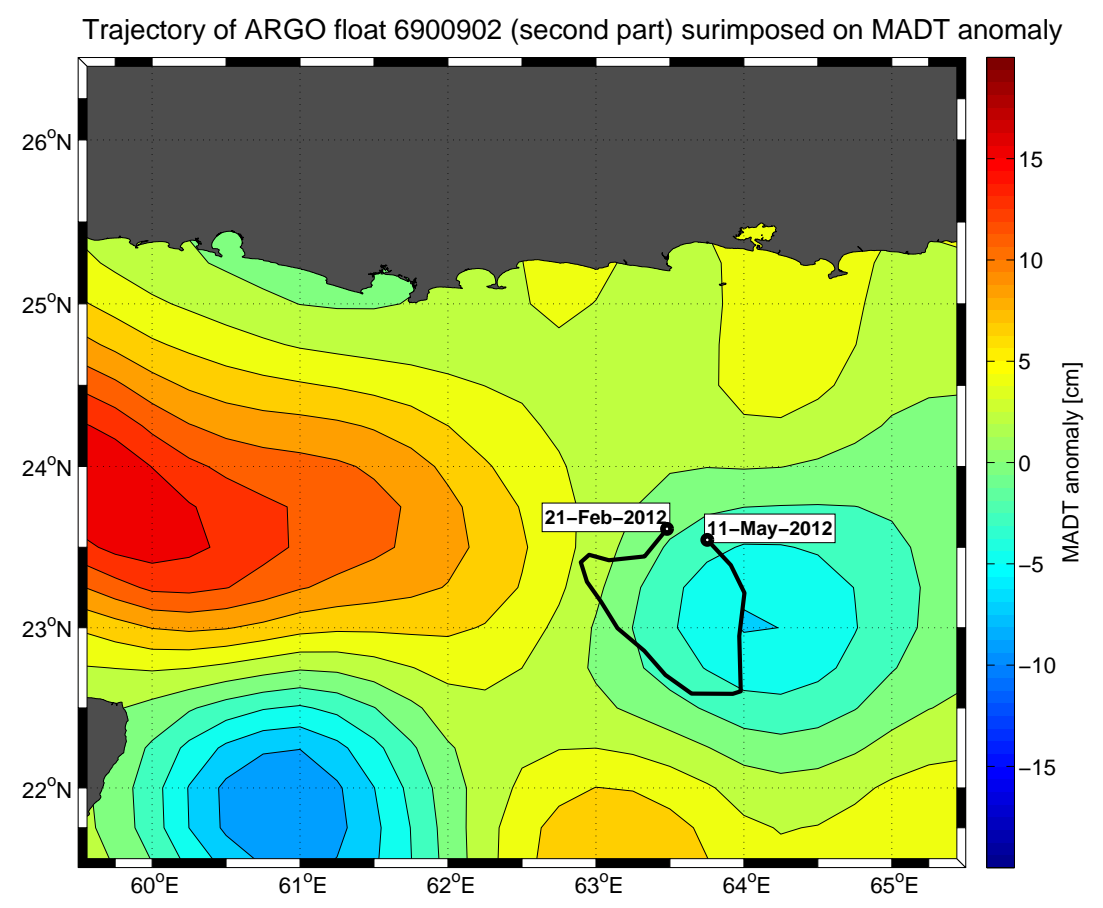

Fig. 8 Trajectory of Argo float 6900902 superimposed on the altimetric map (MADT Anomaly) averaged over the time period of February 21 to May 11, 2012, salinities above 36.5 were measured all along this trajectory.

float data, and recurrence of the dipole situation is searched in altimetric maps.

\subsection{Hydrology}

In appendix $\mathrm{A}$, we show that the horizontal temperature (or salinity) fields obtained with our method or with ODV (Ocean Data View, [22]), coincide. Below, we show results obtained with our interpolation method.

Figure 10 compares the salinity at $250 \mathrm{~m}$ depth in the Sea of Oman, in spring, for the climatology, the modified climatology over years 2002 to 2012, and for years 2008, 2011, 2012, among the years when the dipolar eddy was observed at the surface.

The effect of float data is to slightly reduce the value of salinity by 0.1 in the western end of the Sea of Oman (near $56.5^{\circ} \mathrm{E}$ ); but the relative error is maximum there due to a lack of float data (see Appendix A). On the contrary, they increase salinity by 0.2 between $57.5^{\circ} \mathrm{E}$ and $59.5^{\circ} \mathrm{E}$ (a region where many 


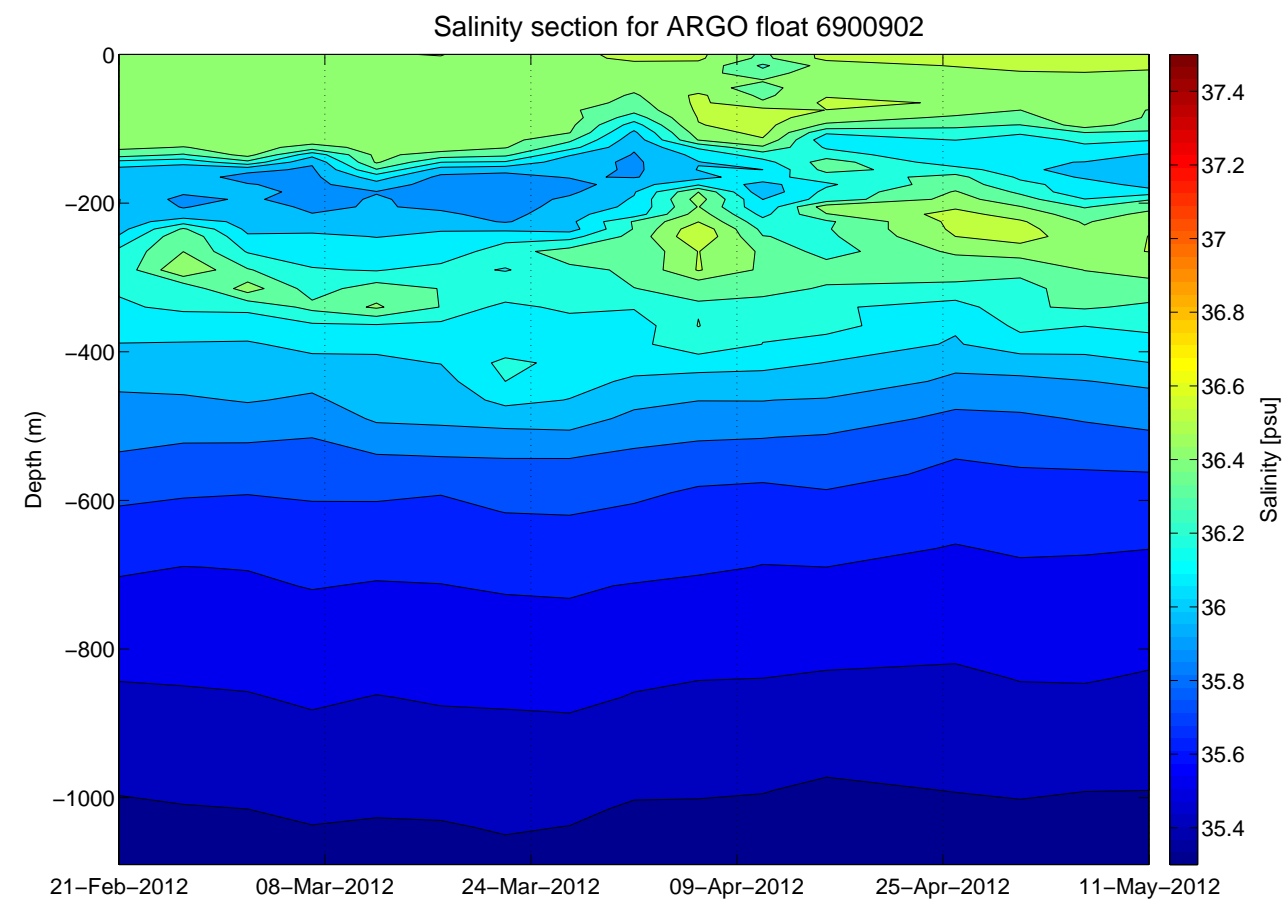

Fig. 9 Time versus depth diagram of salinity, as measured by Argo float 6900902, along its trajectory, from February 21 to May 11, 2012

profiles are available). A marked salinity gradient extends northeastward from Ras al Hamra in the modified climatology, whereas this region had a weak gradient in the original climatology. This is in agreement with the previous finding of recurrent PGW expulsion near Ras al Hamra in spring. Finally, the 36.4 salinity isoline bulges near $61^{\circ} \mathrm{E}, 24^{\circ} \mathrm{N}$ in the modified climatology, an indication of an eastward salt export, in agreement with the observations of float 6900902 .

When only the 2008, 2011 and 2012 data are used, this effect is even more dramatic: salinity close to 36.9 now reach the Iranian coast near $58.5^{\circ} \mathrm{E}$, and a 36.6 salinity patch is found at $62^{\circ} \mathrm{E}, 24^{\circ} \mathrm{N}$. This clearly illustrates the salt export associated with PGW expulsion at Ras al Hamra and its cyclonic and eastward recirculations.

Figure 11 presents similar maps, but for autumn. The inclusion of float measurements has an even stronger effect though few data are available again in the western end of the Sea of Oman (which limits the degree of confidence in results there). Several floats south of Ras al Hadd measured salinities in excess of 37.2. Since such salinities were not present along the Omani coast 

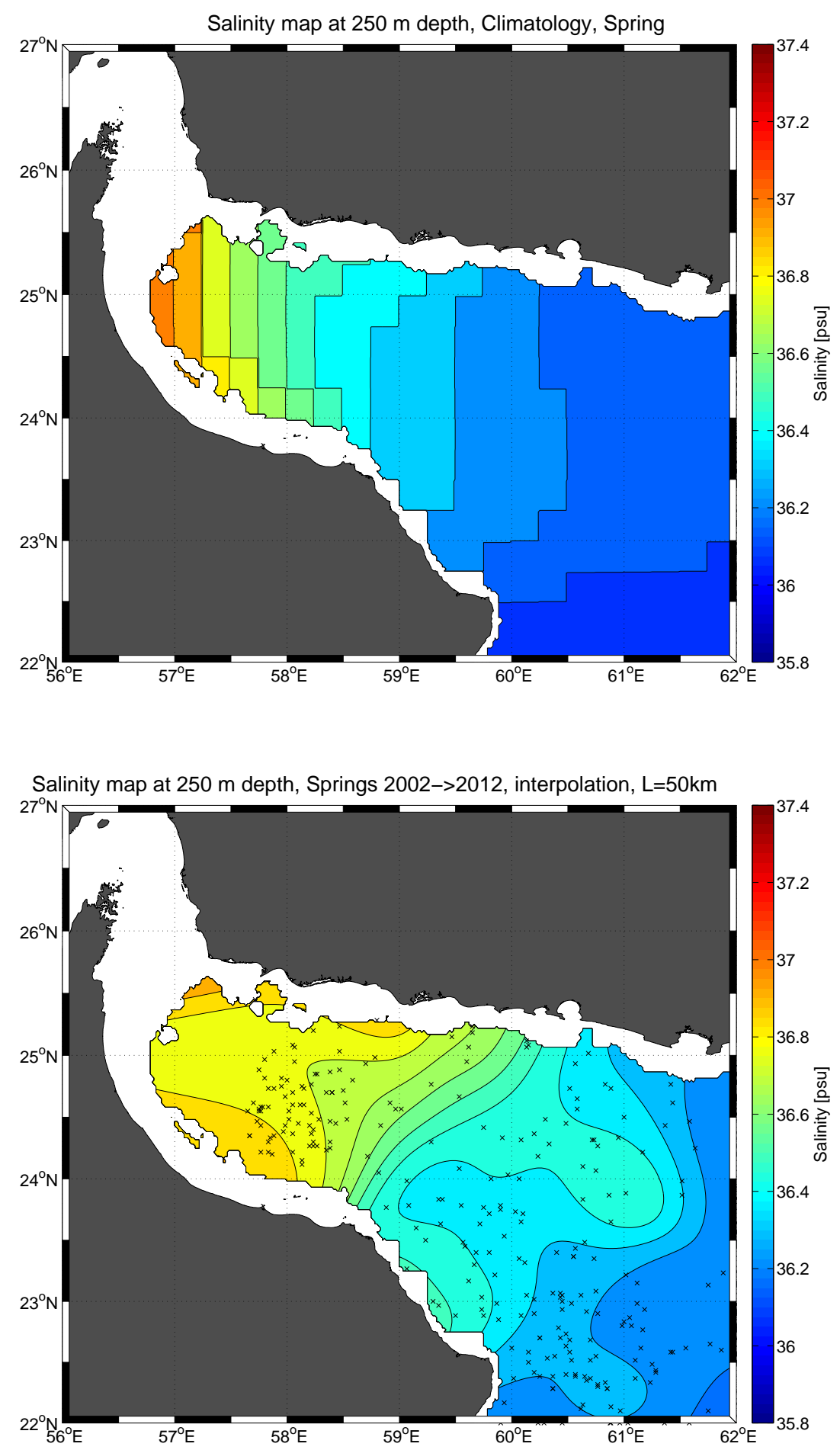
Salinity map at $250 \mathrm{~m}$ depth, Springs 2008, 2011 \& 2012, interpolation, L=50km

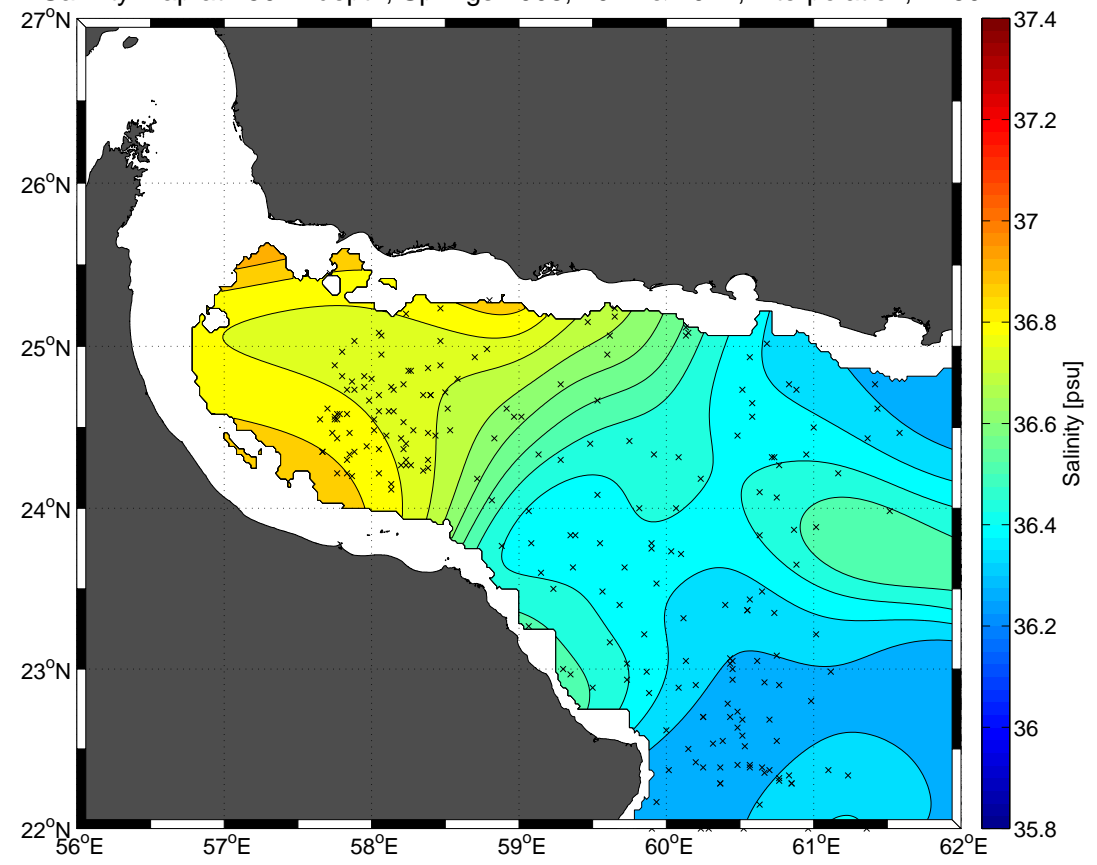

Fig. 10 Horizontal map of salinity in the Sea of Oman at $250 \mathrm{~m}$ depth, for spring: from climatology (previous page, top); from climatology modified by Argo float data over the 2002 - 2012 period (previous page, bottom); from climatology modified by Argo float data for years 2008, 2011 and 2012 (present page). Each cross represents an individual float profile.

up to the Straits of Hormuz, during this season, these strong anomalies must have been occasional and local bursts of salty water. Such bursts could be related to pulses in the outflow of PGW at Hormuz [1], [11], [25], [2], but the concentration of this salty anomaly near Ras al Hadd more likely indicates an instability of the PGW slope current at that location in autumn.

4.2 Sea surface elevation, surface and deep currents

Maps of sea surface elevation (from satellite altimetry) show that the dipolar eddy was present and stationary for several months near Ras al Hamra in 1994, 1995, 1997, 1998, 2005, 2007, 2008, 2011 and 2012, and in a more transient manner in 1999, 2001 and 2002.

But the density of Argo floats was sufficient to detect PGW ejection at Ras al Hamra only after 2007. Thus, we use altimetry and hydrology of spring 2008, 2011 and 2012 to show how the dipolar eddy velocity extracted PGW from 


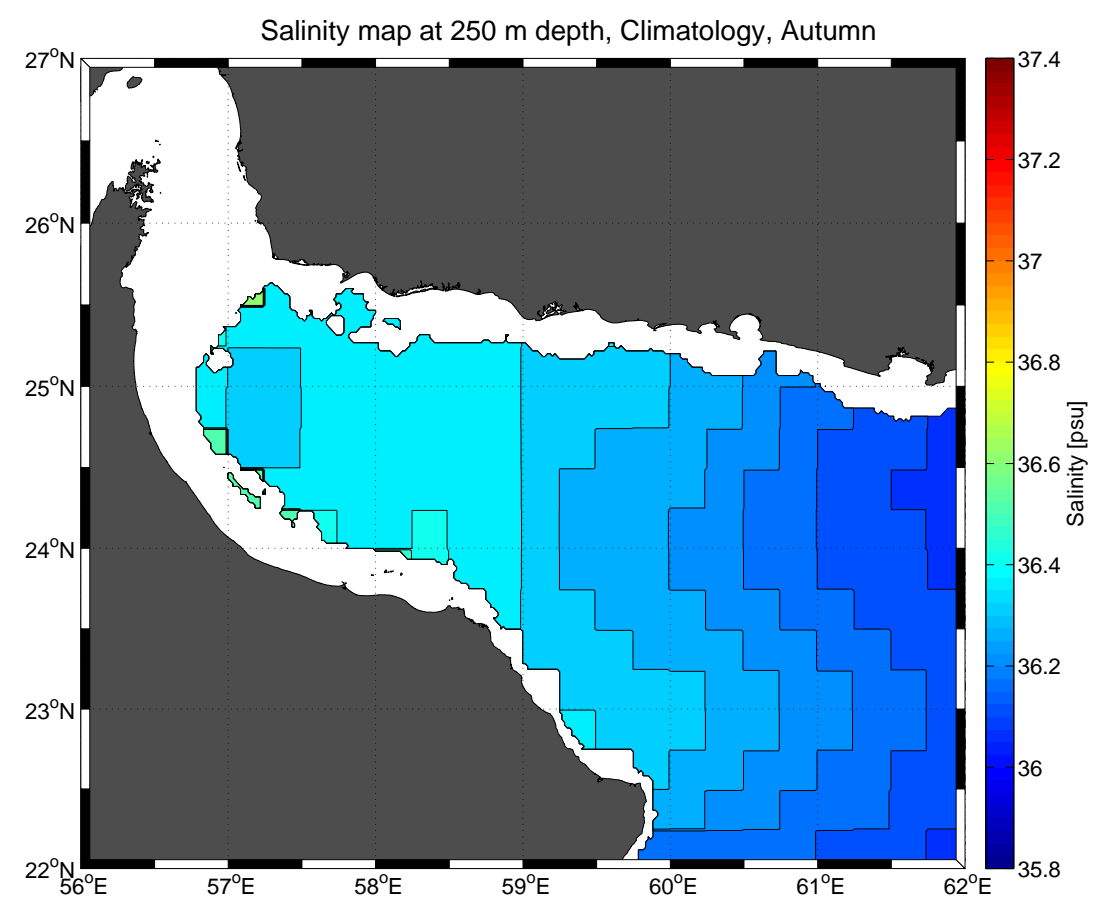

Salinity map at $250 \mathrm{~m}$ depth, Autumns 2002->2012, interpolation, $\mathrm{L}=50 \mathrm{~km}$

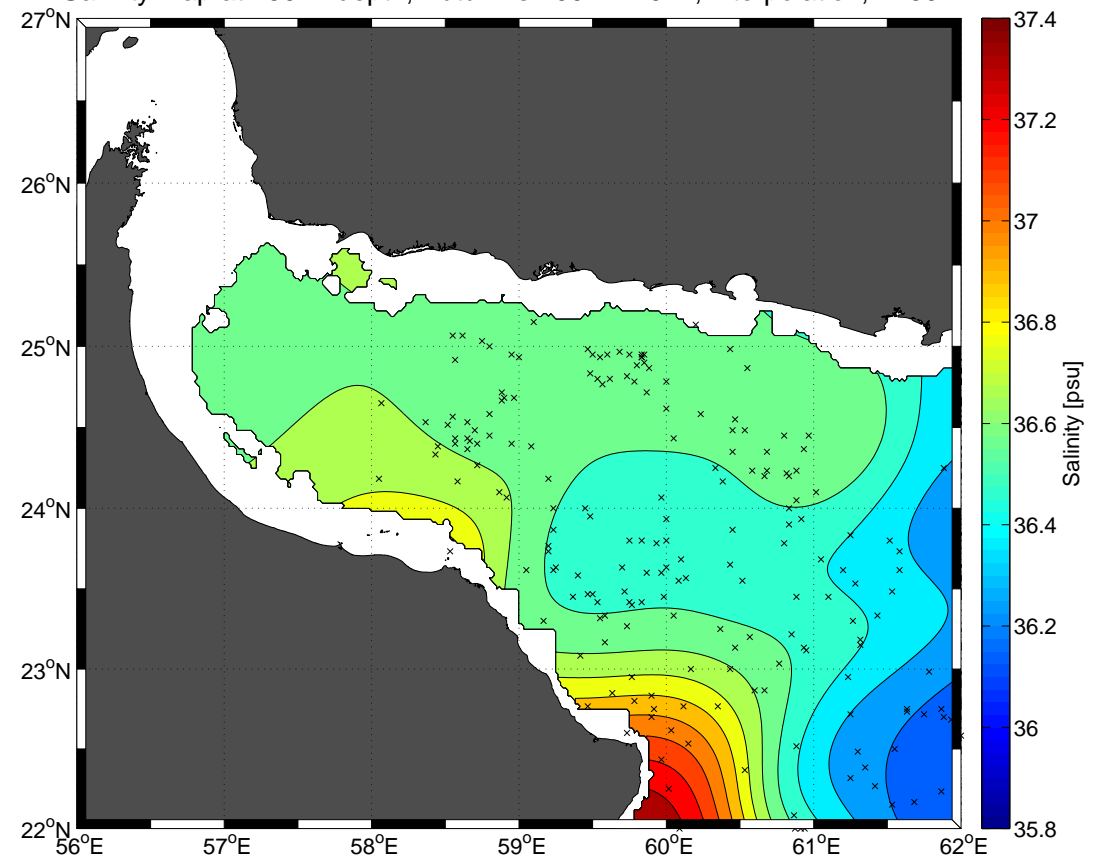

Fig. 11 Horizontal map of salinity in the Sea of Oman at $250 \mathrm{~m}$ depth, for autumn: from climatology (top); from climatology modified by Argo float data over the $2002-2012$ period (bottom). 

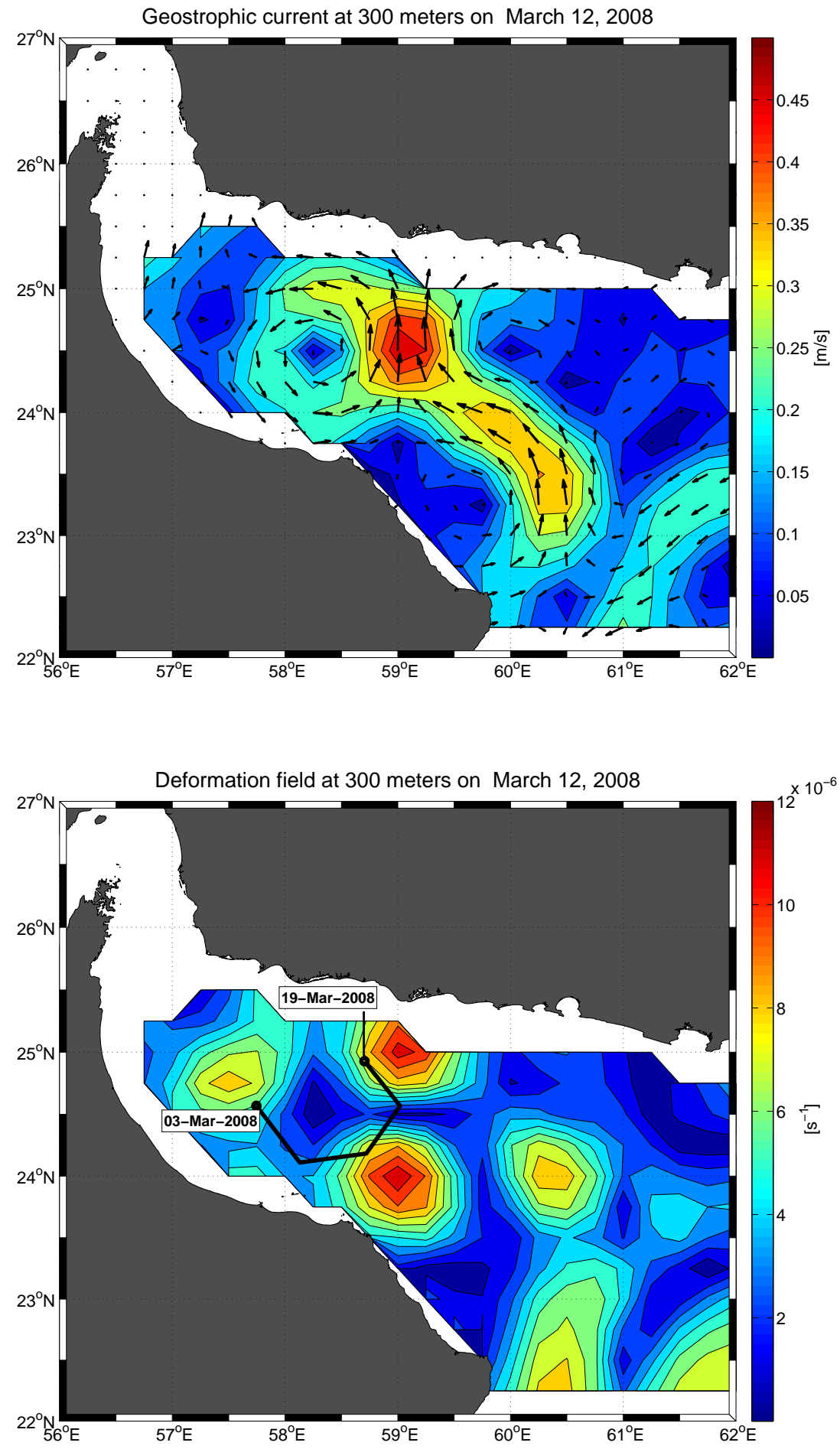


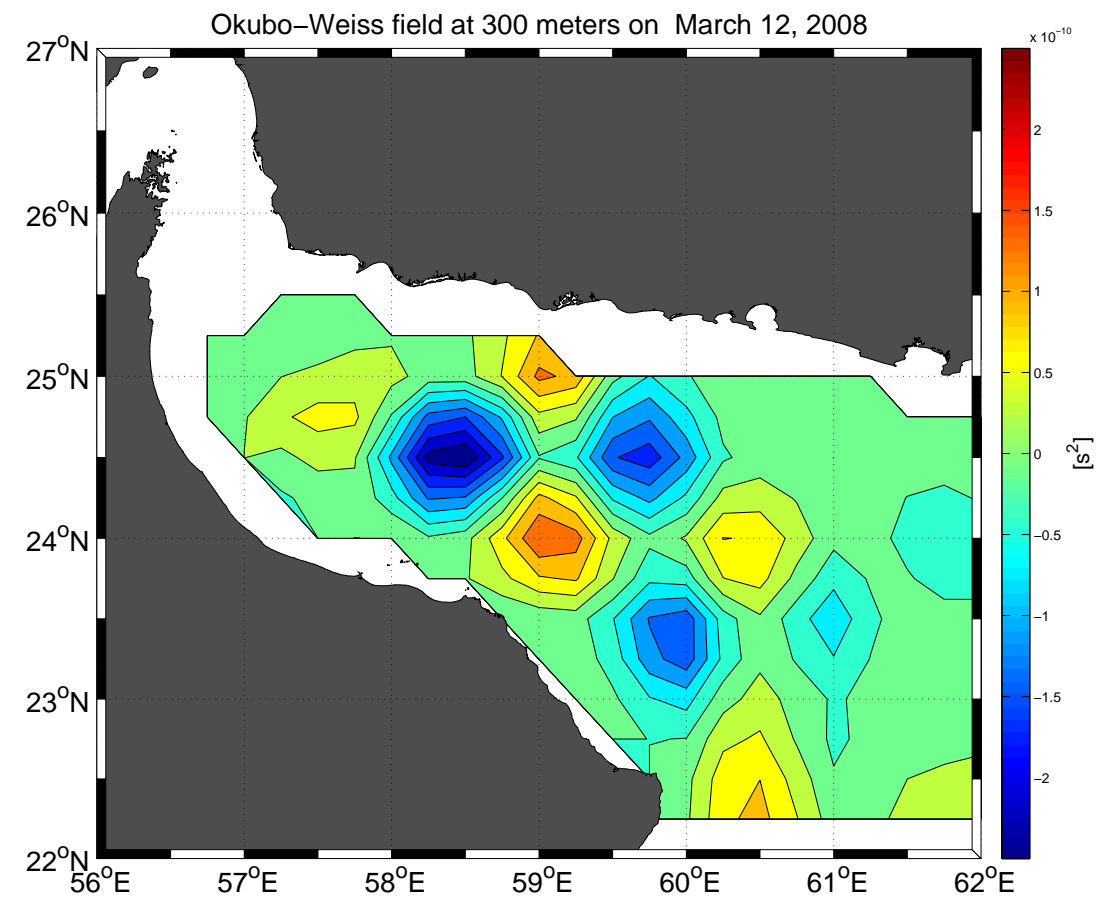

Fig. 12 Velocity and deformation fields at $300 \mathrm{~m}$ depth on March 12, 2008: Geostrophic currents obtained from the thermal wind balance with hydrology and altimetry, with reference velocity at the surface (previous page, top); deformation field at this depth (previous page, bottom); Okubo Weiss criterion at this depth (this page).

the slope currents. Furthermore, since the dynamical patterns were similar in 2008, 2011 and 2012, we present figures only for March 2008.

In appendix A, we show that the relative error in sea surface elevation is moderate at the location of the dipolar eddy.

On figure 12, we present the geostrophic currents at $300 \mathrm{~m}$ depth computed via thermal wind balance, with the hydrological data and using the surface current as a reference. This surface current itself was calculated from the sea surface elevation given by satellite altimetry of March 12, 2008. The currents at this depth closely followed the surface cyclones and anticyclones (see for instance figure 2). The strongest currents were located between the two eddies near $59^{\circ} \mathrm{E}, 24.5^{\circ} \mathrm{N}$. The flow converged towards this point from Ras al Hamra and then diverged towards the Iranian coast. Figure 12 also shows the deformation field at $300 \mathrm{~m}$ depth. Deformation $\sigma$ was computed as follows:

$$
\sigma_{1}=\partial_{x} v+\partial_{y} u, \quad \sigma_{2}=\partial_{x} u-\partial_{y} v, \quad \sigma^{2}=\sigma_{1}^{2}+\sigma_{2}^{2}
$$


We can clearly see that the float followed the regions of maximum deformation. This supports our interpretation that the surface eddy pair exerted a strong deformation on the PGW slope current. This deformation pulled some PGW out of the slope into the deeper part of the Sea of Oman.

The Okubo-Weiss theory (([16], [26]) states that a Lagrangian conserved quantity has a spatial gradient increasing or decreasing with time, depending on the difference between deformation and relative vorticity. When relative vorticity dominates deformation, the gradient diminishes (and conversely). Therefore we have calculated the Okubo-Weiss quantity $\sigma^{2}-\omega^{2}$ (where $\omega=\partial_{x} v-\partial_{y} u$ is relative vorticity), from the horizontal velocity field at $300 \mathrm{~m}$ depth.

This quantity is plotted in figure 12 for March 12, 2008, also. Along 24.5 ${ }^{\circ} \mathrm{N}$, two regions of negative Okubo Weiss quantity correspond to the two eddies where any materially conserved tracer would recirculate and be trapped. On the contrary, the two regions of positive Okubo Weiss quantity, along $59^{\circ} \mathrm{E}$ correspond to strong deformation which can pull fragments of PGW away from the slope currents. Note also that this quadrupolar structure is very characteristic of the deformation field created by an eddy dipole (see for instance [5] for another oceanic example).

Figure 13 presents the time average, and the EOFs, of mean ADT over spring 2008, 2011 and 2012. Clearly, the time average of MADT indicates an eastward increase of the sea surface height. If the spatial mean is substracted from MADT, the geostrophic circulation is cyclonic west of $58^{\circ} \mathrm{E}$ and anticyclonic west of $59^{\circ} \mathrm{W}$. This dipolar structure is robust in a seasonal average repeated over 2008, 2011 and 2012. The EOFs were also computed from the time series of mean ADT over spring of these three years. The first EOF shows an anticyclonic anomaly near Ras al Hadd and represents $73 \%$ of the variability during this period. It has a spatial structure similar to that of the time averaged MADT. The second EOF, which represents $9.5 \%$ of the variability, also has a dipolar structure, but closer to Ras al Hamra, with a cyclonic region east of $58.5^{\circ} \mathrm{E}$ and an anticyclonic region between $59^{\circ} \mathrm{E}$ and $61^{\circ} \mathrm{E}$. Finally, the third EOF, with $5.6 \%$ significance, has a cyclone near $57.5^{\circ} \mathrm{E}$ and an anticyclone near $59^{\circ} \mathrm{E}$. In summary, the first and third EOF reproduce the spatial structure of the dipole while the second EOF reproduces an opposite signed dipole, which is likely to represent the first-order fluctuations of the seasonal structure around its mean.

From the CNES/AVISO Live Access Server (LAS), one can obtain the time evolution of surface eddies in the Gulf of Oman, for every year when the dipole appeared, and also for the year before. This time series is shown in appendix B (see figures 19 and 20). The evolution is always similar: in September of the year before each spring dipole, the circulation in the Gulf of Oman is dominantly cyclonic. In winter, an anticyclonic circulation appears at the mouth of the Gulf. This anticyclonic patch moves westward until it reaches Ras al Hamra in February-March. This evolution suggests that a westward travelling wave could be responsible, in part or totally, for the development of this anti- 


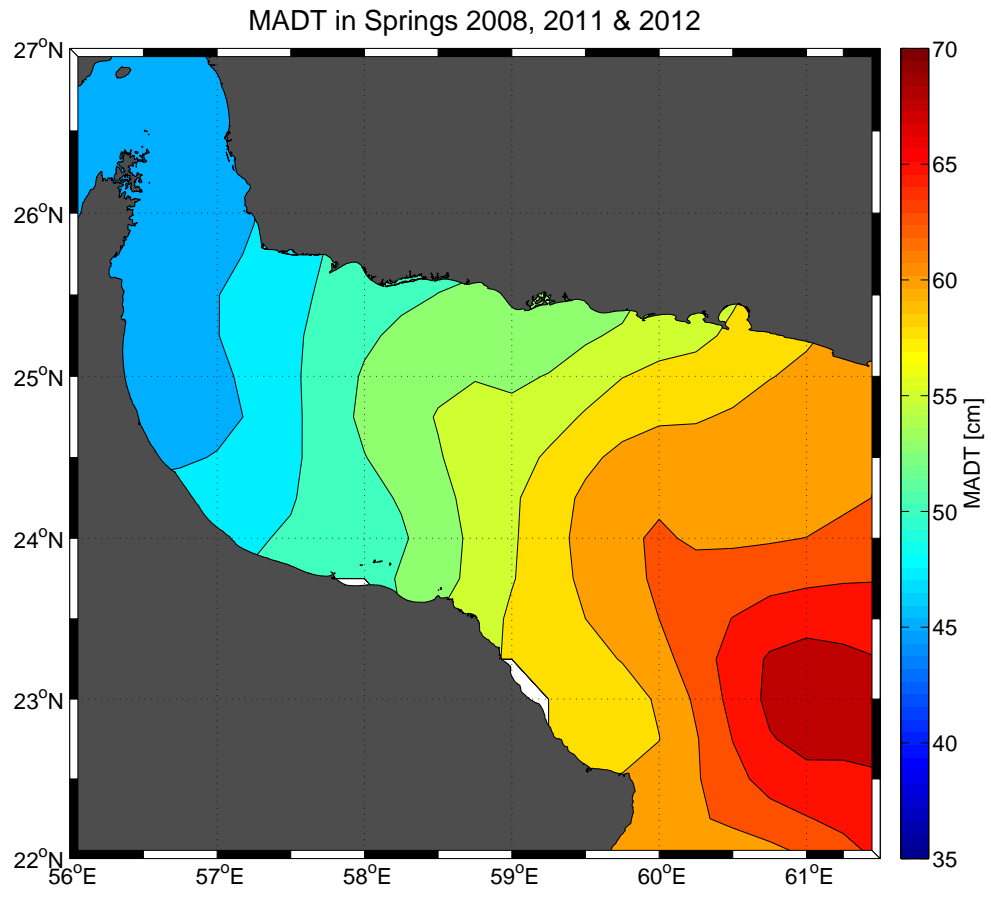

First EOF (73\%)

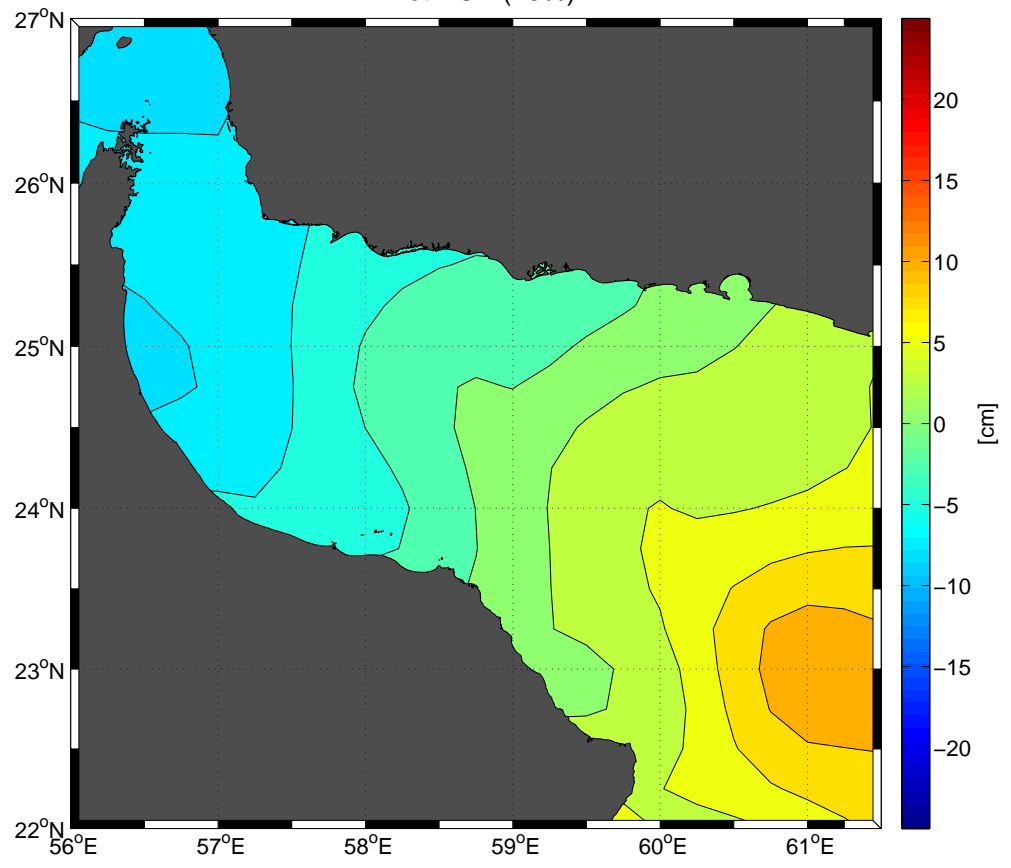



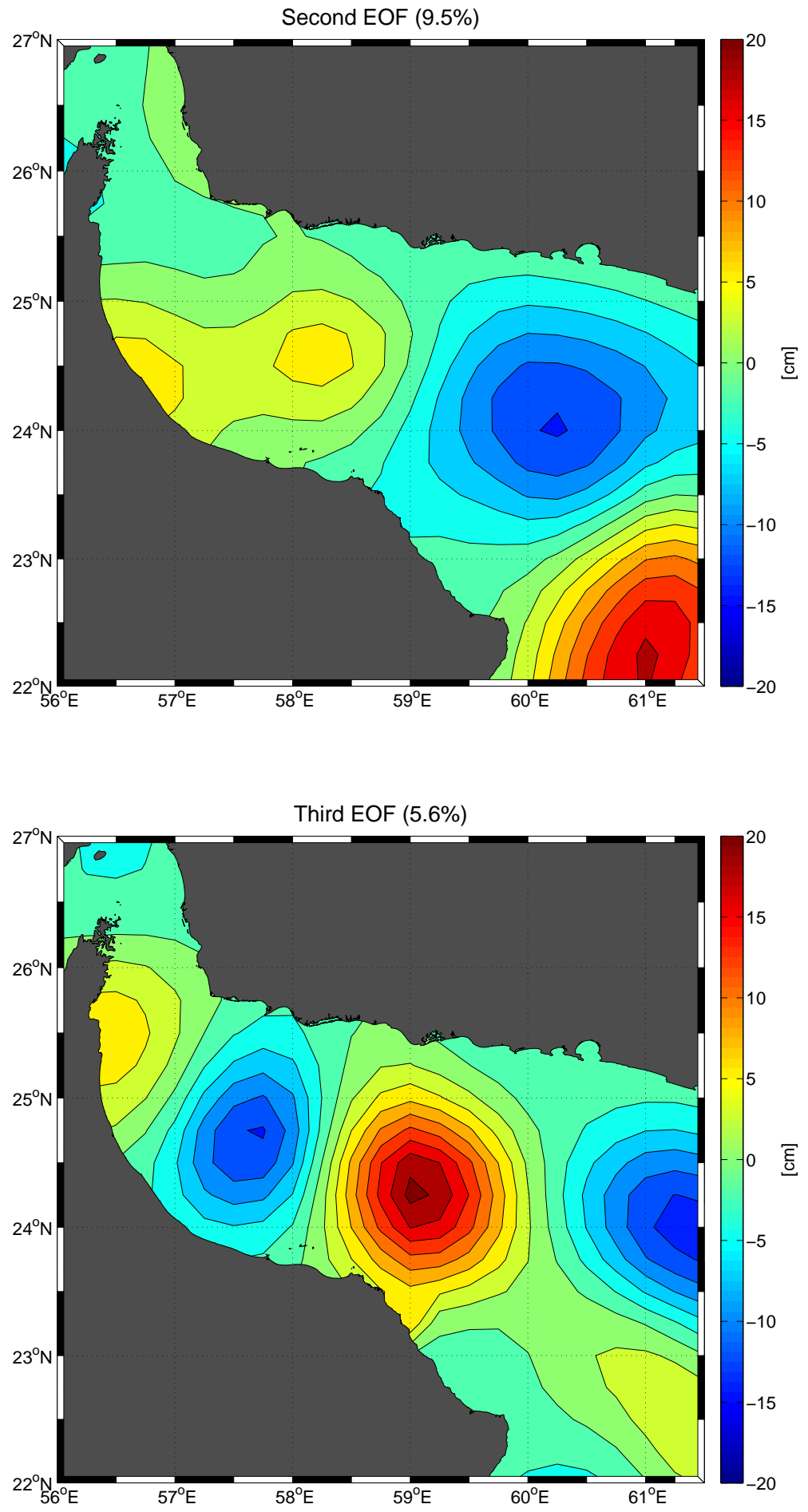

Fig. 13 Time average of MADT over spring 2008, 2011 and 2012 (previous page, top); first EOF of MADT over the same years (previous page, bottom); second EOF of MADT over the same years (this page, top); third EOF of MADT (this page, bottom). 


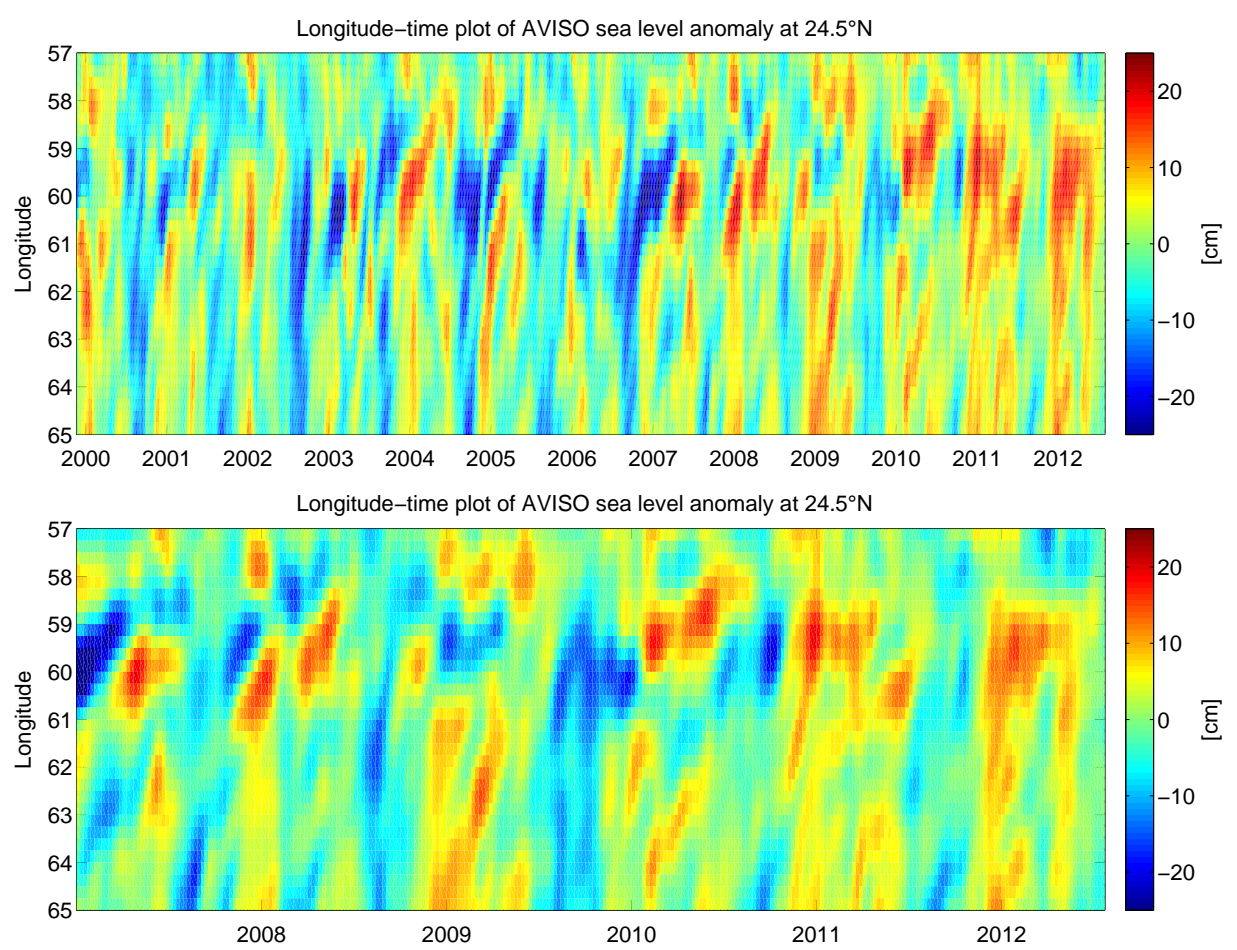

Fig. 14 (Top) Hovemuller diagram of MADT anomaly $(\mathrm{cm})$ at $24.5^{\circ} N$ between 200 and 2012; (bottom) Zoom between 2007 and 2012.

cyclonic patch.

The dipolar situation is then established until June or July. In July or August, the anticyclone weakens and the circulation returns to cyclonic in autumn and early winter.

To investigate the existence of such a westward wave, we present a Hovemuller diagram of the MADT anomaly at $24.5^{\circ} \mathrm{N}$ from 2000 to 2012 . The sea surface height evolution shows westward propagating anomalies. It also indicates an alternation between positive and negative anomalies with an annual cycle. Similar wave propagation across the Indian Ocean has already been shown to be long baroclinic Rossby waves with annual period [4]. For Rossby waves, the phase speed is

$$
c=\frac{\omega}{k}=-\frac{\beta}{k^{2}+1 / R_{d}^{2}}
$$

with $\beta$ the meridional gradient of the Coriolis parameter, $k$ the wave number magnitude (here the zonal wavenumber), $R_{d}$ the Rossby deformation radius. Estimates for these parameters are $\beta=210^{-11} \mathrm{~m}^{-1} \mathrm{~s}^{-1}, k=2 \pi /(500 \mathrm{~km})$, and the first internal radius of deformation is $R_{d}=40 \mathrm{~km}$. This leads to a 
phase speed $c=2.5 \mathrm{~cm} / \mathrm{s}$ in agreement with the observations. Thus a long Rossby wave on the first baroclinic mode is an appropriate mechanism to explain the westward travelling sea surface anomaly along $24.5^{\circ} \mathrm{N}$.

Figure 14 also shows an intensification of the sea surface height anomalies near $61^{\circ} E$ between December and March. As in [4], this intensification may be due to the wind stress near $60^{\circ} \mathrm{E}$ in winter. We will now investigate the wind stress to support this hypothesis.

\section{Discussion: a intensification of the anticyclonic eddy due to wind-stress forcing}

Figure 15 displays the wind stress curl for December 2011 and March 2012 (the high resolution wind data have been available only since 2010). In December, this curl is positive near the Iranian coast and negative near Ras al Hadd. In March, the curl is negative near Ras al Hamra. During the other months, the curl is essentially positive in the Sea of Oman.

Ekman pumping is the wind stress curl multiplied by a factor $1 /(\rho f)$. Associated with the wind field, upwelling occurs along the Iranian coast and downwelling along the Omani coast. This downwelling can strengthen the anticyclonic motion near Ras al Hadd in winter. These upwellings and downwellings lead to the presence of colder and fresher waters along the Coast of Iran (as can be seen for instance in the recordings of float 2901370 in November 2011), and to warmer and saltier waters along the coast of Oman, as shown by the strong salinity anomalies near Ras al Hadd in late fall, early winter.

Thus, the wind sress curl at the mouth of the Sea of Oman in winter can amplify the Rossby waves propagating westward along $24.5 \mathrm{o} \mathrm{N}$. This can in turn strengthen the anticyclonic part of the dipole observed at Ras al Hamra from March on. The strong positive anomalies of sea surface (related with Rossby waves) at $60^{\circ} \mathrm{E}$ during the years of dipole formation are consistent with this interpretation.

\section{Conclusions}

In summary, Argo float trajectories, and temperature and salinity recordings, in the Sea of Oman, have shown that the currents at 200-300 $\mathrm{m}$ depth could be directed offshore in spring near Ras al Hamra, and that fragments of warm and salty Persian Gulf Water could then be stripped away from the slope current of PGW. The analysis of altimetric maps from the CNES/AVISO center has shown that a mesoscale dipolar eddy was often present in spring near Ras al Hamra, with a cyclone west of this cape and an anticyclone east of it. This orientation leads to a flow between the eddies that is offshore. These eddies 

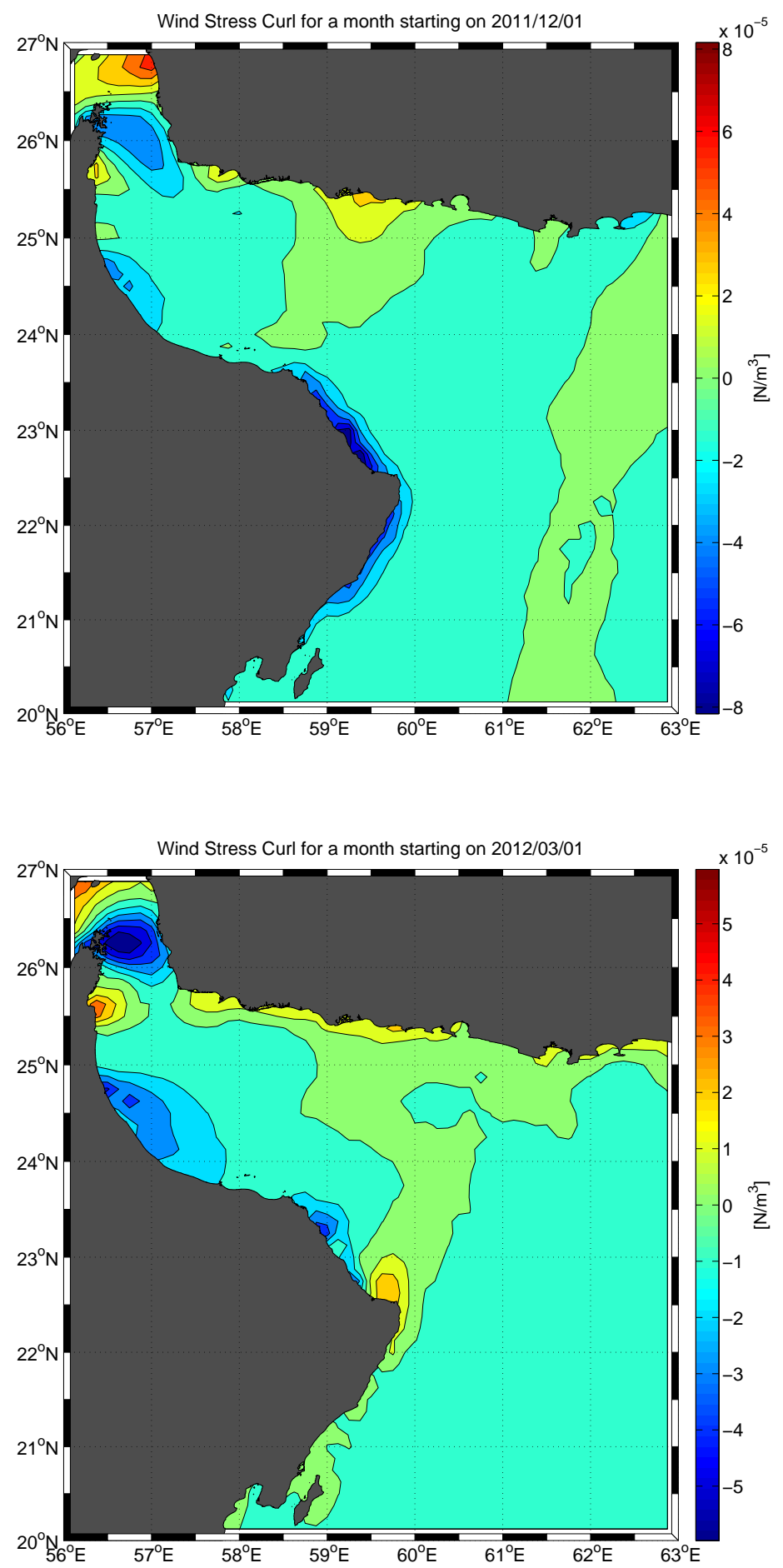

Fig. 15 (Top) Wind stress curl in the Gulf of Oman and the Northern Arabian Sea, in December 2011; (bottom) wind stress curl in March 2012. 
are deep reaching dynamically, as was evidenced by the trajectory of the Argo floats. This dipole can have been formed by the autumn cyclonic circulation joined with anticyclonic vorticity production at the mouth of the Sea of Oman in winter.

In more details, the paper presented the following results:

- though a few previous papers have mentioned the possible detachment of PGW from the coast, the traditional view was that the PGW outflow hugs the Omani coast and veers southeastward at Ras al Hadd in summer and southwestward in winter; here we have shown that PGW could be found both under the form of fragments in the middle of the Sea of Oman and as patches near the Iranian coast. This new picture results from the individual analysis of Argo float recording and from the construction of a new seasonal climatology including these data. These warm and salty anomalies in the middle or north of the Sea of Oman are all the more pronounced as only the years where the dipole was present, were included in the climatology.

- furthermore, it appears that PGW does not only recirculate in the western Sea of Oman, but that it can also extend eastward along the Iranian and Pakistani coasts. There, other eddying motions can extract fragments from this coastal patch and advect them offshore, as float 6900902 showed. The complex pattern of PGW extension due to turbulent motions will certainly be made more clear and more complete in future studies, with more float data.

- the trajectory of the Argo floats often followed loops of different sizes, but most frequently measured radii varied between 30 and $60 \mathrm{~km}$. The floats followed the surface currents, with an amplitude ratio of about $2 / 3$ in velocity, especially in the presence of surface eddies. These eddies have a diameter varying between 150 and $250 \mathrm{~km}$, are often cyclonic in autumn in the Sea of Oman while anticyclonic eddies appear in late winter. A recurrent feature is the presence of the dipolar eddy near Ras al Hamra in spring.

- the analysis of the circulation at 200-300 m depth (PGW depth) showed that the dipole creates a strong deformation along its axis, which is likely to be the cause of PGW extraction from the coast. This also appears in the structure of the Okubo Weiss quantity.

- the dipolar eddy observed in spring of several years seems to result from long baroclinic Rossby waves propagating at the mouth of the Sea of Oman; it can have been amplified by the wind stress near $60^{\circ} \mathrm{E}$ during winter. It was noted that dipole formation occured during the years when the positive SSH intensified near the coast of Oman, in the Rossby wave; this supports our interpretation. Another mechanism which could also contribute to the formation of this dipole is the interaction of the PGW outflow with bottom topography, leading to the instability of this outflow current. Indeed, in winter, the PGW outflow is deeper ([2]) and a baroclinic instability process ([18]) triggered by topographic irregularities along the continental slope, could lead to eddy detachment. Nevertheless, the specific correlation of this latter mechanism with the years of dipole formation still has to be established. 
Two interesting extensions of this work may be the following:

a) use a regional numerical model to obtain more insight in the three-dimensional dynamics of the Sea of Oman, both for the effect of mesoscale eddies on the PGW outflow, and for the generation and evolution of these mesoscale eddies; b) use other data (or again a numerical model), to provide a more complete view of the extent of PGW due to mesoscale variability.

Acknowledgements The authors thank Universite de Bretagne Occidentale and DGA for their support under REI program COMINO and ASTRID program SYNBIOS, during the course of this work. They also thank Dr A. Bentamy (LOS, IFREMER) for providing wind data, and CNES/AVISO for the altimetric data. The authors are grateful to the referees for their in-depth analysis of this work and for an essential suggestion which improved the quality of this paper.

\section{Appendix A: Validation of methods for horizontal maps of hydrology and altimetry}

Firstly, we present two temperature maps, for spring, over years 2002-2012, one obtained with our interpolation method and the other created directly with ODV (Ocean Data View, [22]; see figure 17). The agreement is good, except west of $57.5^{\circ} \mathrm{E}$ (see below for the error on hydrology).

Secondly, we show the map of significative points for hydrology obtained by interpolation/extrapolation of float data: this corresponds to the weight attributed to each point of the grid, related to the repartition of measures in the region (the marked points on figure 17 for example). Below 5 points, in particular west of $57.5^{\circ}$, where no float ever profiled, the interpolation is too poor to be trusted. Elsewhere, the number of points is sufficient, more specifically near Ras al Hamra where PGW ejection occurs.

Thirdly, we also show the error map for sea surface elevation (see figure 18): this error is maximum near the coasts, but at the location of the eddies that we describe in the text, the error is only $\pm 6 \mathrm{~cm}$. This must be compared with a difference of 20 to $25 \mathrm{~cm}$ in altimetry, between the crest and trough of the anticyclonic and cyclonic eddies considered. Therefore the altimetric maps that we show have a 20 to 30 percent error for eddies near a coast, and a smaller error in the deep ocean.

\section{Appendix B: Evolution of altimetry over a year}

Figures 19 and 20 show the evolution of ADT for each month, time averaged over 3 years : 2008, 2011 and 2012. 

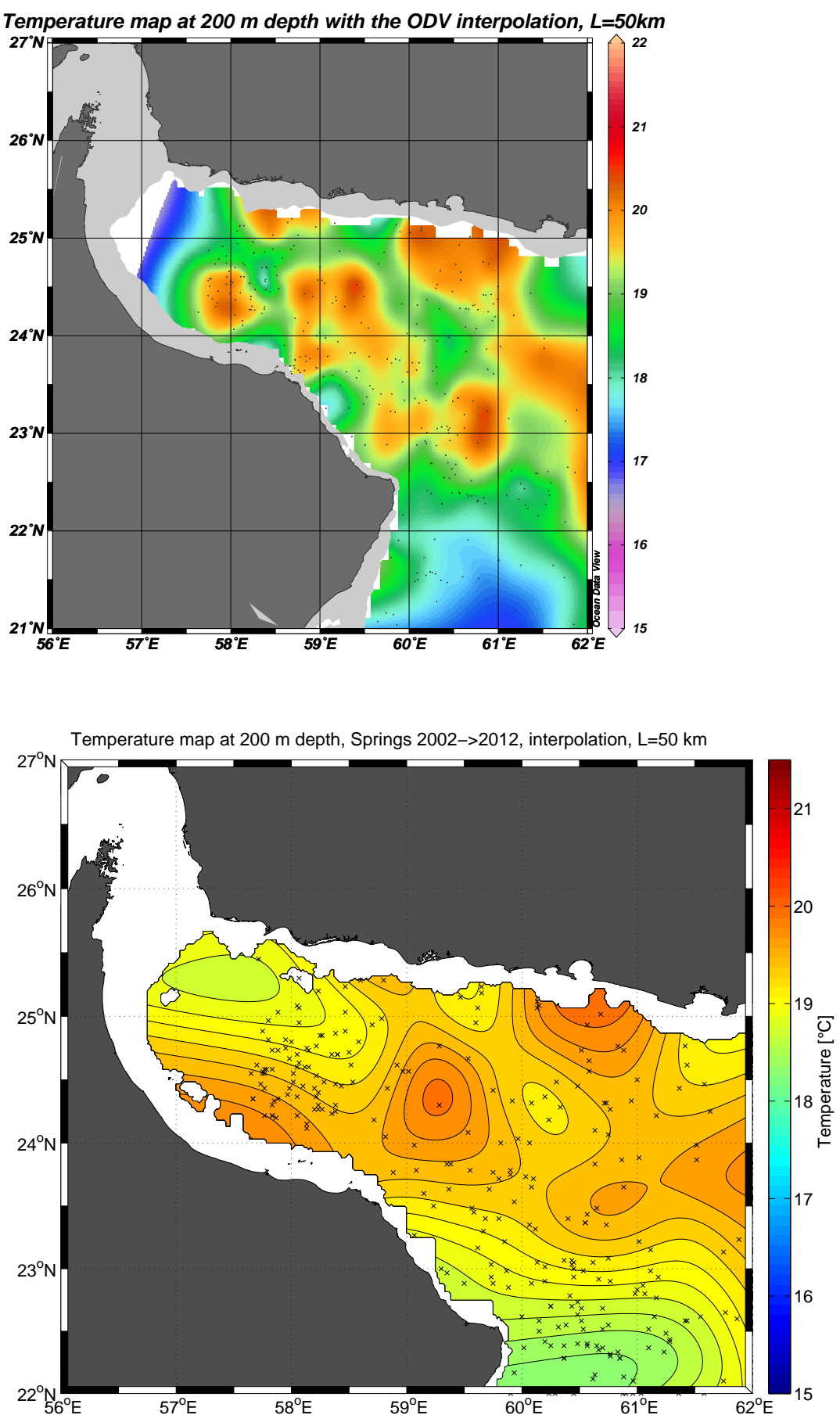


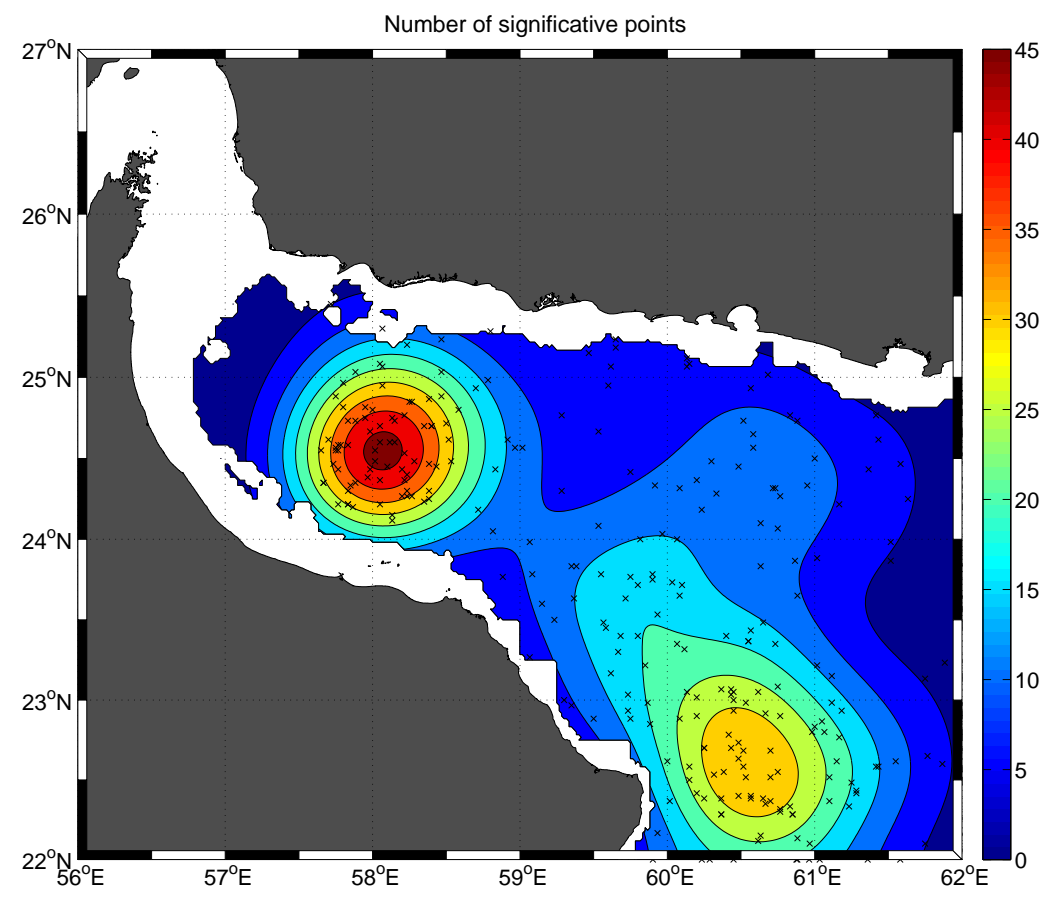

Fig. 16 Temperature field at $200 \mathrm{~m}$ depth obtained by using all float profiles of spring 2002-2012, as individual profiles with the ODV software (previous page, top); temperature field obtained with the interpolation method described in this paper (previous page, bottom). Number of significative points map for hydrology, interpolated/extrapolated from Argo profiles, for spring (this page).

\section{References}

1. Banse K., Irregular flow of Persian (Arabian) Gulf water to the Arabian Sea. Journal of Marine Research, 55, 6, 1049-1067 (1997).

2. Bidokhti A.A. and M. Ezam, The structure of the Persian Gulf outflow subjected to density variations. Ocean Science, 5, 112 (2009).

3. Bower A.S., Hunt H.D. and J.F. Price, Characteristics and dynamics of the Red Sea and Persian Gulf outflows. Journal of Geophysical Research, 105, C3, 6387-6414 (2000).

4. Brandt P., Stramma L, Schott F., Fischer J;, Dengler M. and Quadfasel D., Annual Rossby waves in the Arabian Sea from TOPEX/POSEIDON altimeter and in situ data. Deep-Sea Research II, 49, 1197-1210, (2002).

5. Carton X., Chérubin L., Paillet J., Morel Y., Serpette A. and B. Le Cann, Meddy coupling with a deep cyclone in the Gulf of Cadiz. Journal of Marine Systems, 32, 13-42 (2002).

6. Carton X.,L'Hegaret P. and R. Baraille, Mesoscale variability of water masses in the Arabian Sea as revealed by ARGO floats. Ocean Science, 8, 1-22 (2012)

7. Ducet, N., P.-Y. Le Traon, and G. Reverdin, 2000: Global high resolution mapping of ocean circulation from TOPEX/Poseidon and ERS-1 and -2. Journal of Geophysiscal Research, 105, 19477-19498.

8. Ezam M., Bidokhti A.A. and A.H. Javid, Numerical simulation of spreading of the Persian Gulf outflow in the Oman Sea. Ocean Science, 6, 887-900 (2010). 


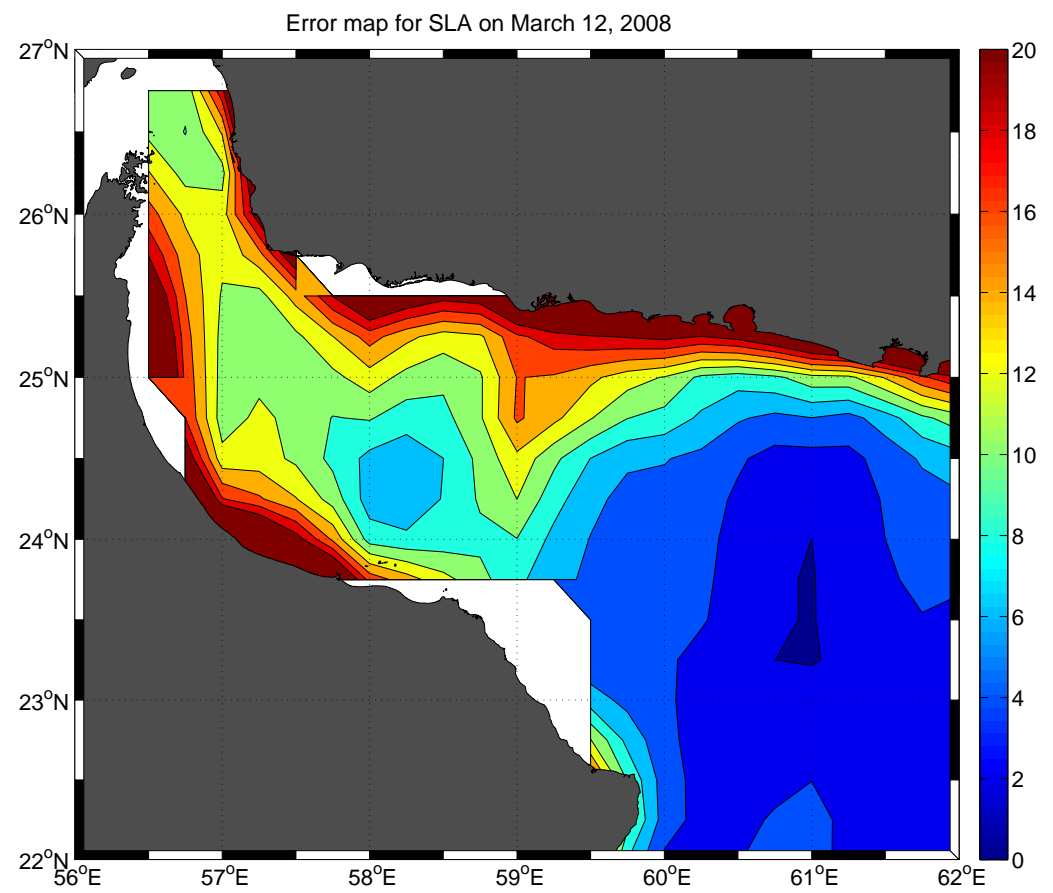

Fig. 17 Error map for sea surface elevation, on March 12, 2008, in the Sea of Oman.

9. Fu L.L. and A. Cazenave, Satellite altimetry and Earth sciences - a handbook of techniques and applications. International Geophysics Series, 69, Academic Press, London, 463 pp. (2001).

10. Gaspar, P., and F. Ogor, Estimation and analysis of the sea state bias of the new ERS-1 and ERS-2 altimetric data, (OPR version 6). Technical Report. IFREMER/CLS Contract n 96/2.246 002/C. (CLS/DOS/NT/96.041) (1996).

11. Johns W.E., Yao F., Olson D.B., Josey S.A., Grist J.P. and D.A. Smeed, Observations of the seasonal exchange through the Straits of Hormuz and the inferred heat and freshwater budget of the Persian Gulf. Journal of Geophysical Research, 108 (C12), 3391 (2003).

12. Labroue S., P. Gaspar, J. Dorandeu, F. Mertz and OZ. Zanif, Overview of the Improvements Made on the Empirical Determination of the Sea State Bias Correction, 15 years of progress in radar altimetry Symposium, Venice, Italy (2006).

13. Le Traon P.Y. and G. Dibarboure, Mesoscale mapping capabilities of multiple-satellite altimeter missions. Journal Of Atmospheric And Oceanic Technology, 16(9), 1208-1223, (1999).

14. Le Traon P.Y., G. Dibarboure and N. Ducet, Use of a high-resolution model to analyze the mapping capabilities of multiple-altimeter missions. Journal Of Atmospheric And Oceanic Technology, 18(7), 1277-1288, (2001)

15. Matsuyama M., Senjyu T., Ishimaru T., Kitade Y., Koike Y., Kitazawa A., Miyazaki T. and H. Hamada, Density front in the Strait of Hormuz. Journal of Tokyo University of Fisheries, 81, 85-92 (1994).

16. Okubo A., Horizontal dispersion of floatable particles in the vicinity of velocity singularities such as convergences. Deep-Sea Research, 17, 445454, (1970). 

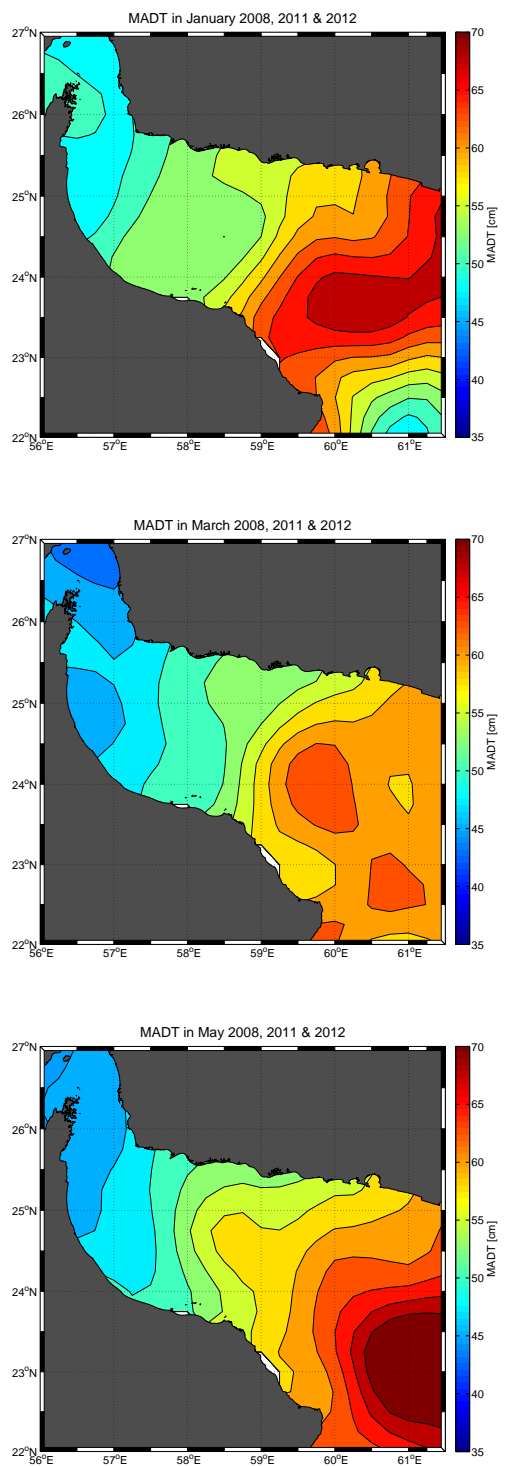

MADT in February 2008, 2011 \& 2012

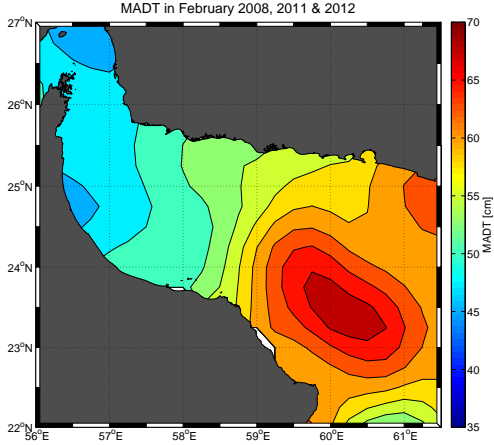

MADT in April 2008, 2011 \& 2012

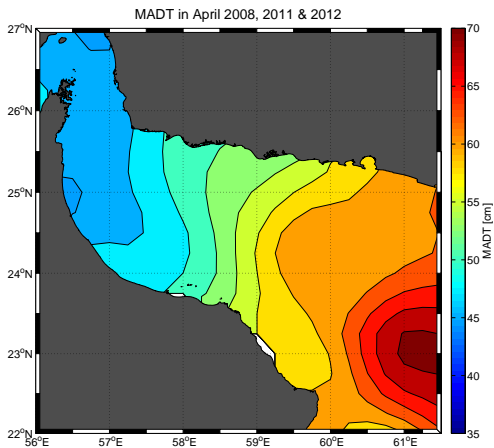

MADT in June 2008, 2011 \& 2012

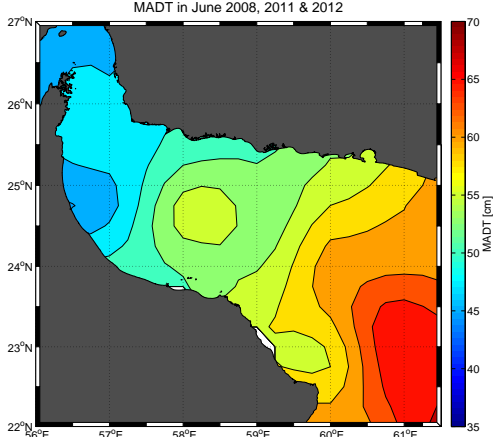

Fig. 18 Time average of ADT over January (top, left); February (top, right); March (center, left); April (center, right); May (bottom, left); June (bottom, right).

17. Pous S., Carton X. and P. Lazure, Hydrology and circulation in the Strait of Hormuz and the Gulf of Oman; results from the GOGP99 Experiment. Part I. Strait of Hormuz. Journal of Geophysical Research, 109, C12037, doi:10.1029/2003JC002145, 1-15 (2004a).

18. Pous S., Carton X. and P. Lazure, Hydrology and circulation in the Strait of Hormuz and the Gulf of Oman; results from the GOGP99 Experiment. Part II. Gulf of Oman. Journal of Geophysical Research, 109, C12038, doi:10.1029/2003JC002146, 1-26 (2004b). 

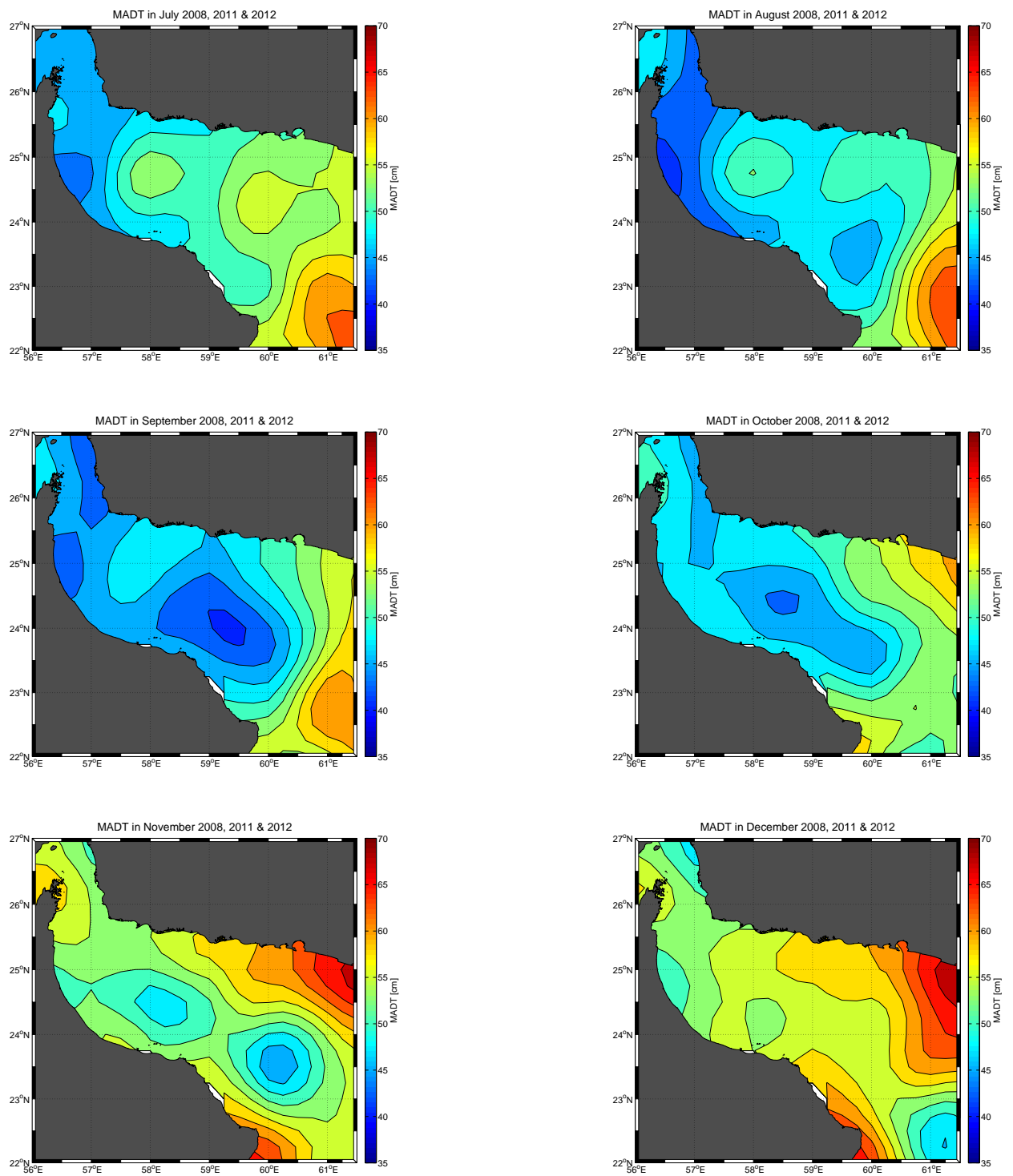

Fig. 19 Time average of ADT over July (top, left); August (top, right); September (center, left); October (center, right); November (bottom, left); December (bottom, right).

19. Pous S., Carton X. and P. Lazure, A process study of the tidal circulation in the Persian Gulf. Open Journal of Marine Sciences, 2, 4, 131-140 (2012).

20. Pous S., Carton X. and P. Lazure, A process study of the wind-induced circulation in the Persian Gulf. Open Journal of Marine Sciences, 3, 1, 1-11 (2013).

21. Reynolds R.M., Physical Oceanography of the Gulf, Strait of Hormuz, and the Gulf of Oman - Results from the Mt Mitchell Expedition. Marine Pollution Bulletin, 27, 35-59 (1993). 
22. Schlitzer R., Ocean Data View user's guide/ Technical Report. Alfred Wegener Institute (2005).

23. Senjyu T., Ishimaru T., Matsuyama M. and Y. Koike, High salinity lens from the Strait of Hormuz. Offshore environment of the ROPME sea area after the war-related oil spill. 35-48 (1998)

24. Swift S.A. and A.S. Bower, Formation and circulation of dense water in the Persian Gulf. Journal of Geophysical Research, 108, C1, 3004, doi:10.1029/ 2002JC001360 (2003).

25. Thoppil P.G. and P.J. Hogan, On the Mechanisms of Episodic Salinity Outflow Events in the Strait of Hormuz. Journal of Physical Oceanography, 39, 1340-1360 (2009).

26. Weiss J., The dynamics of enstrophy transfer in two-dimensional hydrodynamics. Physica D, 48, 273-294 (1991)

27. Yao F. and W.E. Johns, A HYCOM modeling study of the Persian Gulf. 1. Model configurations and surface circulation. Journal of Geophysical Research, 115, C11017, doi:10.1029/2009JC05781 (2010)

28. Yao F. and W.E. Johns, A HYCOM modeling study of the Persian Gulf. 2. Formation and export of Persian Gulf Water. Journal of Geophysical Research, 115, C11018, doi:10.1029/2009JC05788 (2010) 